\title{
Toll-Like Receptor 5 Signaling Ameliorates Liver Fibrosis by Inducing Interferon $\beta$-Modulated IL-1 Receptor Antagonist in Mice
}

\author{
Zixiong Zhou, Jong-Won Kim, Jing Qi, Seong Kug Eo, Chae Woong Lim, and Bumseok Kim
}

From the Biosafety Research Institute, and the BK21 Plus Program, College of Veterinary Medicine, Jeonbuk National University, Iksan, Jeonbuk, South Korea

Accepted for publication

November 5, 2019.

Address correspondence to Bumseok Kim, D.V.M., Ph.D. Laboratory of Pathology, College of Veterinary Medicine, Jeonbuk National University, Iksan, Jeonbuk 54596, South Korea. E-mail: bskims@jbnu. ac.kr.

\begin{abstract}
Bacterial flagellin, recognized by cell surface of Toll-like receptor (TLR) 5 , is a potent activator of many types of cells, leading to the activation of innate or adaptive immunity, which are pivotal in regulating fibrotic process. However, the exact role of TLR5 signaling in hepatic fibrogenesis remains unclear, and this study aims to elucidate its underlying mechanisms. Flagellin was injected to hepatotoxin- and cholestasis-induced liver fibrosis murine models. Flagellin-induced TLR5 activation significantly decreased the severity of liver fibrosis. Interestingly, the expression levels of IL-1 receptor antagonist (IL1RN) and interferon (IFN) $\beta$ markedly increased in fibrotic livers on flagellin treatment. Consistently, in vivo activation of TLR5 signaling markedly increased IFN $\beta$ and IL1RN expression in the livers. Notably, flagellin injection significantly exacerbated the severity of liver fibrosis in IFN- $\alpha / \beta$ receptor 1 (IFNAR1) knockout mice. Furthermore, hepatic expression of IL1RN in the fibrotic livers of IFNAR1 knockout mice was significantly lower than those of wild-type mice. In support of these findings, flagellin-mediated IL1RN production is not sufficient to alleviate the severity of hepatic fibroinflammatory responses in IFNAR1-deficient milieu. Finally, hepatic stellate cells treated with IL1RN had significantly decreased cellular activation and its associated fibrogenic responses. Collectively, manipulation of TLR5 signaling may be a promising therapeutic strategy for the treatment of liver fibrosis. (Am J Pathol 2020, 190: 614-629; https://doi.org/10.1016/j.ajpath.2019.11.012)
\end{abstract}

Liver fibrosis is the consequence of dysregulated wound healing responses against repeated and persistent liver injury induced by viral infection, drug abuse, steatohepatitis, or cholestasis. This long-lasting hepatic damage leads to cirrhosis known as the advanced and irreversible stage of liver fibrosis and finally progresses to hepatocellular carcinoma in patients with cirrhosis. ${ }^{1}$ Furthermore, hepatic fibrotic responses are closely associated with the onset of several life-threating complications, which include ascites, varices, renal failure, hepatic encephalopathy, and hepatopulmonary hypertension. ${ }^{2}$ Among numerous cellular events associated with the progression of liver fibrosis, the most critical cellular response is known as the activation of hepatic stellate cells (HSCs), which results in excessive production of extracellular matrix proteins in injured liver. Once activated in response to tissue injury, the cells undergo a change of their gene expression pattern, leading to increase of the proliferation rate, and the expression levels of profibrogenic genes. ${ }^{3}$ Despite recent great advances in fibrosis resolution and antifibrotic therapy, liver transplantation is the only therapeutic option in patients with advanced liver fibrosis and cirrhosis. Therefore, it is essential to develop effective therapeutic strategies based on understanding the pathophysiologic process of liver fibrosis at moderate and mild stages because of its reversibility. ${ }^{4}$

The mammalian innate immune system is composed of numerous highly conserved pattern recognition receptors,

\footnotetext{
Supported by Basic Science Research Program, National Research Foundation grants NRF-2017R1D1A3B03030521 (B.K.), 2017R1A6A3A11032024 (J-W.K.), and 2020R1A2C1007178 (B.K.) funded by the Ministry of Education, Republic of Korea.

Z.Z. and J.-W.K. contributed equally to this work.

Disclosures: None declared.
} 
including Toll-like receptors (TLRs) and nucleotide oligomerization domain-like receptors that can recognize specific endogenous or exogenous ligands; this recognition provokes an innate immune response by recruiting various immune cells to the site of infection, injury, or inflammation. ${ }^{5}$ Among these innate receptors, TLR5 has the ability to bind flagellin, a component of bacterial flagella, which consequently induces proinflammatory and innate immune responses via myeloid differentiation primary response 88 (Myd88)dependent activation of transcription factors, NF- $\kappa \mathrm{B}$ and activation protein 1 (AP-1), in immune and nonimmune cells. ${ }^{6}$ In addition, flagellin-mediated Myd88-independent pathway has been demonstrated by Mizel et al, ${ }^{7}$ providing that flagellin binds to TLR5/4 heterodimeric complex and subsequently activates TIR domain-containing adapterinducing interferon (IFN) $\beta$ (TRIF) and its downstream signaling molecule, IFN regulatory factor 3 (IRF3), leading to the production of IFN $\beta$. Thus, flagellin-induced TLR5 signaling has recently emerged as a potent innate or adaptive immune modulator in infected or noninfected milieu. ${ }^{8}$ In line with this notion, a recent study ${ }^{9}$ found that intestinal epithelial cell-specific deletion of TLR5 in mice develops low-grade inflammation and metabolic syndrome. In addition, these mice are prone to colitis because TLR5 signaling in intestinal epithelial cells modulates intestinal inflammation through regulating intestinal microbiota. ${ }^{9}$ Consistently, administration of CBLB502, a TLR5 agonist, alleviates ulcerative colitis by reducing inflammation. ${ }^{10}$ Similar effects of TLR5 signaling in liver were observed in recent published findings, indicating that CBLB502 treatment protects concanavalin $\mathrm{A}$-induced hepatic injury by limiting T-cell/ natural killer T-cell activation and cytokine production. ${ }^{11}$

Liver, as an immunologic organ, plays a key role in pathogen detection and host defense because it is continually exposed to systemic or gut-derived pathogens. The ability of hepatic immunologic surveillance to detect pathogens is dependent on pattern recognition receptors expressed by various liver cells. A recent study noted that the liver is a dominant sink for the action of flagellin, and hepatocytes are the key liver cell type in response to flagellin. ${ }^{12}$ Hepatocyte TLR5 was found to accelerate bacterial clearance and suppress inflammatory responses in liver. ${ }^{13} \mathrm{~A}$ recent study mentioned that TLR5 activation in the liver might act as a functional vascular firewall that captures commensal bacteria that have entered gut or systemic vascular circuits. ${ }^{14}$ Therefore, TLR5 activation induced by flagellin might induce immunosuppressive response, which is deduced to be a mechanism used to refrain from low-grade inflammatory responses of chronic liver diseases.

Several studies have suggested that gut microbiota dysbiosis and pathological bacterial translocation are involved in several chronic liver diseases. ${ }^{15}$ In response to liver injury, the level of bacterial components was increased in portal or systemic circulation. Consistent with these findings, TLR5 signaling also plays a key role in the pathogenesis of liver fibrosis as determined by using TLR5 knockout (KO) mice, indicating that after multiple long-term carbon tetrachloride $\left(\mathrm{CCl}_{4}\right)$ injections, TLR5-lacking mice have lower fibrosis responses in liver tissues. ${ }^{16}$ However, whole body or intestinal epithelial cell-specific TLR5-deficient mice exhibited spontaneous colitis, with increased burden of commensal bacteria and intestinal permeability. ${ }^{17}$ In this regard, the findings of liver fibrosis in TLR5-deficient mice might not exactly reflect the pathophysiologic aspect of TLR5 signaling pathway on the development and/or progression of chronic liver diseases, including liver fibrosis. Therefore, the objective of the present study was to examine the role of TLR5 signaling by flagellin-mediated activation in the pathogenesis of hepatotoxin- and cholestasis-induced liver fibrosis.

\section{Materials and Methods}

\section{Animals}

Seven-week-old male wild-type (WT), type 1 IFN- $\alpha / \beta$ receptor 1 (IFNAR1) KO, and CD11c diphtheria toxin receptor transgenic (CD11c-DTRtg) mice (on C57BL/6 background) were used in this study, and the mice were housed in a standardized temperature of $24^{\circ} \mathrm{C} \pm 2^{\circ} \mathrm{C}$ at $50 \% \pm 5 \%$ humidity. WT mice were bought from Toconic Farms, Inc. (Samtako Bio Korea, O-San, South Korea). IFNAR1 KO mice were bought from B\&K Universal (Hull, UK), then backcrossed to C57BL/6 strain for at least 10 generations. CD11c-DTRtg mice were bought from the Jackson Laboratory (Bar Harbor, ME). All animal experiments followed the criteria of the requirements of the Animal Care and Ethics Committees of Chonbuk National University.

\section{Animal Models of Liver Fibrosis}

To induce liver fibrosis, two kinds of murine fibrosis models were used in this study. In the first model of liver fibrosis, $\mathrm{CCl}_{4}$ [2:5 v/v in corn oil, $2 \mathrm{~mL} / \mathrm{kg}$ body weight (BW); SigmaAldrich, St. Louis, MO] or vehicle (corn oil; Sigma-Aldrich) were injected intraperitoneally three times a week during the experimental period (4 weeks). In the second model of liver fibrosis, bile duct ligation (BDL) and sham surgery were performed, as previously described. ${ }^{18}$ After induction of liver fibrosis, mice were anesthetized with Zoletil $(0.2 \mathrm{~mL} / \mathrm{kg} \mathrm{BW})$ through intramuscular injection. Heart, blood, and liver tissues were then collected for further analysis. Commercially available flagellin (InvivoGen, San Diego, CA), derived from Salmonella Typhimurium, was used for in vivo stimulation of TLR5 signaling in the current study. Groups of WT or IFNAR1 KO mice were injected intraperitoneally with phosphate-buffered saline (PBS) or flagellin ( $1 \mu \mathrm{g}$ per mouse) every other day during the experimental period.

\section{Histopathologic Examination}

Collected liver tissues were fixed with $10 \%$ phosphatebuffered formalin, processed, and paraffin embedded 
according to standard procedure. Embedded tissue was cut to $4-\mu \mathrm{m}$ thickness using a microtome (HM-340E; Thermo Fisher Scientific Inc., Waltham, MA) and placed on glass slides. Hematoxylin and eosin (H\&E) staining was conducted routinely according to standard protocol.

To clearly assess the severity of fibrosis, tissue sections were stained with Sirius-red staining (Sigma-Aldrich). After the sections were stained, the percentage of red-stained collagen fibers was assessed by measuring Siriusred-positive area per total liver section. Total liver section images were analyzed for each animal using a light microscope (BX-51; Olympus Corp., Tokyo, Japan) and digital imaging software (analySIS TS Auto version 5.1; Olympus Corp.).

To detect the cellular apoptosis in the livers, terminal deoxynucleotidyl transferase-mediated dUTP nick-end labeling (TUNEL; ApopTag Peroxidase In Situ Apoptosis Detection Kit; Merck Millipore, Burlington, MA) assay was used on paraffin-embedded sections according to the kit's protocols. The hepatocellular apoptosis was determined by measuring the TUNEL-positive nucleus in the liver sections. A total of 10 high-power fields were analyzed from the liver tissue of each mouse. Quantitative data are expressed as the percentage of TUNEL-labeled cells. Analyses were performed using a light microscope and digital image software (analySIS TS).

\section{Biochemical Measurements}

Liver fibrosis-related liver injury was determined by measuring serum levels of alanine aminotransferase and aspartate aminotransferase using spectrophotometric assay kits (AM101-K; ASAN Pharmaceutical, Hwasung, Korea). Absorbance values of serum biochemical were measured at a 490-nm wavelength using an EMax spectrophotometer (Molecular Devices, Sunnyvale, CA).

\section{Depletion of DCs and KCs in Mice}

To deplete dendritic cells (DCs), CD11c-DTRtg mice were injected intraperitoneally with diphtheria toxin $(4 \mathrm{ng} / \mathrm{g} \mathrm{BW})$ for 2 consecutive days. To deplete Kupffer cells (KCs), WT mice were injected with clodronate liposome $(200 \mu \mathrm{L}$ per mouse) for 2 consecutive days. Control groups of WT mice were injected intraperitoneally with PBS.

\section{In Vivo Activation or Inhibition of TLR5 Signaling Pathway}

To activate in vivo TLR5 signaling pathway, mice were treated with flagellin ( $1 \mu \mathrm{g}$ per mouse) by intraperitoneal injection. Mice were sacrificed at the indicated time points after flagellin injection. To inhibit TLR5 signaling pathway, TH1020 (Sigma-Aldrich; 1 or $10 \mu \mathrm{g}$ per mouse) was injected intraperitoneally 30 minutes before flagellin injection. Mice were sacrificed after 2 hours after flagellin injection. Serum and liver tissues were collected for further experiments.

\section{LPS-Induced ALI}

After 30 minutes of flagellin injection ( $1 \mu \mathrm{g}$ per mouse), WT or IFNAR1 KO mice were administered lipopolysaccharide (LPS) (Sigma-Aldrich) at a dose of $20 \mathrm{mg} / \mathrm{kg} \mathrm{BW}$ to induce acute liver injury (ALI). Mice were injected with the same volume of PBS as control. After 6 hours of LPS administration, mice were anesthetized with Zoletil before blood and liver tissues were collected for future analysis.

\section{Isolation of NPC Fractions in Livers}

Cells from the livers of WT and IFNAR1 KO mice were separated into various types of cells, as described previously. ${ }^{19}$ Briefly, collagenase perfusion $(1 \mathrm{~mL} /$ minute) was performed to digest liver tissues. A suspension of liver cells from the livers of WT or IFNAR1 KO mice were prepared and centrifuged at $50 \times g$ for 2 minutes. The pellet, representing hepatocytes, was gently resuspended with Dulbecco's Modified Eagle's Medium (DMEM; Lonza, Basel, Switzerland) supplemented with $10 \%$ fetal bovine serum (Thermo Fisher Scientific Inc.), $100 \mathrm{IU} / \mathrm{mL}$ of penicillin, and $100 \mu \mathrm{g} / \mathrm{mL}$ of streptomycin. Viability of hepatocytes was estimated using the standard trypan blue (SigmaAldrich) and was $>85 \%$.

After centrifugation of digested liver cell suspension at $50 \times g$ for 2 minutes, the supernatant was collected, and applied onto an $11.5 \%$ and 20\% Optiprep (Sigma-Aldrich) discontinuous density gradient to obtain HSC fraction and nonparenchymal cell (NPC) fraction, respectively. KC and DC fractions were positively selected from the NPC fraction by magnetic cell sorting using indicated antibodies (for $\mathrm{KC}$ : anti-F4/80; for DC: anti-CD11c and anti-PDCA; Miltenyi Biotech, Auburn, CA). An HSC layer between 11.5\% OptiPrep and Gey's Balanced Salt Solution (GBSS) was carefully collected. The HSC fraction was further purified by negative selection using magnetic cell sorting with appropriate antibody to remove remaining KCs. Isolated cells were washed with PBS and resuspended in RPMI 1640 media for cell culture or immediately homogenized for RNA extraction.

\section{Quantitative Real-Time PCR}

As described previously, ${ }^{20}$ Easy-Spin Total RNA extraction kit (GeneAll, Seoul, Korea) was used to isolate total RNA from liver tissues. Following treatment with genomic DNA Remover (TOYOBO Co., Osaka, Japan), RNA was reverse transcribed using a ReverTra Ace qPCR RT Master Mix (TOYOBO Co.) to synthesize cDNA according to the manufacturer's protocol. Then, PCR reactions were performed using a CFX96 Real-Time PCR Detection System (Bio-Rad Laboratories, Hercules, CA) with a PCR Master Mix (SYBR Green; TOYOBO Co.). After the reaction was completed, specificity was verified by melting curve 
analysis. Glyceraldehyde-3-phosphate dehydrogenase was used as internal control. Primers are summarized in Table 1.

\section{Western Blot Analysis}

Protein was extracted from liver tissues or cells by homogenization on ice with an extraction buffer (tissue protein extraction reagent or radioimmunoprecipitation assay buffer; Thermo Fisher Scientific Inc.) followed by centrifugation at $13,000 \times g$ for 15 minutes at $4^{\circ} \mathrm{C}$. Supernatants were collected and protein concentration was measured using Pierce BCA Protein Assay kit (Thermo Fisher Scientific Inc.) in line with the manufacturer's instructions. Then equal amounts of protein samples were electrophoresed on $10 \%$ sodium dodecyl sulfate-polyacrylamide gel electrophoresis (SDS-PAGE) and electrotransferred to polyvinylidene difluoride membranes. Then the membranes were blocked with $5 \%$ bovine serum albumin diluted in Tris-buffered saline $(20 \mathrm{mmol} / \mathrm{L}$ Tris, $150 \mathrm{mmol} / \mathrm{L}$ sodium chloride, $\mathrm{pH}$ 7.4) that contained $0.05 \%$ Tween-20 at room temperature for 2 hours and then incubated with primary antibodies at $4{ }^{\circ} \mathrm{C}$ overnight. The following antibodies were used: rabbit anti-mouse $\alpha$ smooth muscle actin ( $\alpha$-SMA) antibody (Abcam, Cambridge, UK), rabbit anti-mouse signal transducer and activator of transcription 3 (STAT3) antibody (Cell Signaling, Danvers, MA), rabbit anti-mouse phosphoSTAT3 (Cell Signaling), anti-mouse NF- $\mathrm{B}$ (Cell Signaling), rabbit anti-mouse phospho-NF- $\kappa \mathrm{B}$ (Cell Signaling), and anti- $\beta$-actin (Santa Cruz Biotechnology Inc., Dallas, TX). To detect antigen-antibody complexes, the membranes were incubated with horseradish

Table 1 Sequences of Primers Used for Quantitative Real-Time PCR

\begin{tabular}{|c|c|}
\hline Gene & Primer sequences \\
\hline \multirow[t]{2}{*}{ TGFB } & F: 5'-TGAACCAAGGAGACGGAATACAGG-3' \\
\hline & R: $5^{\prime}-$ GCCATGAGGAGCAGGAAGGG-3' \\
\hline \multirow[t]{2}{*}{ Col1 } & F: 5'-ACAGGCGAAACCGGTGACAG- $3^{\prime}$ \\
\hline & R: $5^{\prime}-$ GCCAGGAGAACCAGCAGAGC-3' \\
\hline \multirow[t]{2}{*}{$\alpha S M A(A C T A)$} & F: 5'-TCAGGGAGTAATGGTTGGAA-3' \\
\hline & R: 5'-CAGTTGGTGATGATGCCGTG-3' \\
\hline \multirow[t]{2}{*}{ TIMP1 } & F: 5'-TCTGGCATCTGGCATCCTCTTG-3' \\
\hline & R: 5'-AACGCTGGTATAAGGTGGTCTCG-3' \\
\hline \multirow[t]{2}{*}{ TNFA } & F: 5'-AGGGTCTGGGCCATAGAACT-3' \\
\hline & R: 5'-CCACCACGCTCTTCTGTCTAC-3' \\
\hline \multirow[t]{2}{*}{ IL1B } & F: 5'-CTCGCAGCAGCACATCAACA-3' \\
\hline & R: 5'-CCACGGGAAAGACACAGGTA-3' \\
\hline \multirow[t]{2}{*}{ IL1RN } & F: 5'-TCAGATCTGCACTCAATGCC-3' \\
\hline & R: 5'-CTGGTGTTTGACCTGGGAGT-3' \\
\hline \multirow[t]{2}{*}{ IFN $\beta$} & F: 5'-AGCTCCAAGAAAGGACGAACAT-3' \\
\hline & R: 5'-GCCCTGTAGGTGAGGGTTGATCT-3' \\
\hline \multirow[t]{2}{*}{ TLR5 } & F: 5'-AAGGACAAGGTCTGGAGTTTGGA-3' \\
\hline & R: 5'-GCCTGTTTCGGGAACTGTAGTG-3' \\
\hline \multirow[t]{2}{*}{ GAPDH } & F: 5'-ACGGCAAATTCAACGGCACAG-3' \\
\hline & R: 5'-AGACTCCACGACATACTCAGCAC-3' \\
\hline
\end{tabular}

$F$, forward; $R$, reverse. peroxidase-conjugated secondary antibodies (Santa Cruz Biotechnology Inc.) at 1/2000 in blocking buffer for 1 hour at room temperature. Protein bands were visualized with an enhanced chemiluminescence detection system using ImageQuantTM LAS 500 (GE Healthcare Life Science, Pittsburgh, PA). The relative protein density was determined using ImageQuantTM TL software version 8.1 (GE Healthcare Life Science).

\section{Enzyme-Linked Immunosorbent Assay}

Protein levels of IL1RN in the culture supernatants or tissue lysates were determined using a commercial enzyme-linked immunosorbent assay kit (R\&D Systems, Minneapolis, $\mathrm{MN}$ ), according to the manufacturer's protocols.

\section{In Vitro Experiments}

Isolated hepatocytes $\left(5.0 \times 10^{5}\right.$ cells per well $)$ or $\mathrm{KCs}$ $\left(1.0 \times 10^{6}\right.$ cells per well $)$ from WT or IFNAR1 KO mice were seeded in 12-well plates and then cultured with DMEM or RPMI 1640 media that contained $10 \%$ fetal bovine serum, $100 \mathrm{IU} / \mathrm{mL}$ of penicillin, and $100 \mu \mathrm{g} / \mathrm{mL}$ of streptomycin at $37^{\circ} \mathrm{C}$ in a $5 \%$ carbon dioxide incubator. For co-culture experiments, primary hepatocytes and $\mathrm{KCs}$ (at a $\mathrm{KCs} /$ hepatocytes ratio of 1:4) were co-cultured in 12-well transwell plates (Sigma-Aldrich). The conditioned media were collected for further experiments and analysis. To stimulate TLR5 signaling, cells were stimulated with 100 $\mathrm{ng} / \mathrm{mL}$ of flagellin for 24 hours. In addition, cells were treated with recombinant murine IFN $\beta(500 \mathrm{IU} / \mathrm{mL})$ for 24 hours.

Primary murine HSCs were plated onto 12-well plates and cultured for up to 7 days after isolation for cell activation. The medium was changed every 2 days. To evaluate the role of IL1RN on HSCs, activated primary HSCs (7 days after isolation) were treated with recombined murine IL1RN $(10 \mathrm{ng} / \mathrm{mL})$ for 24 hours. In addition, activated HSCs were treated with flagellin-treated conditioned media, as mentioned above.

\section{Statistical Analysis}

All data are presented as means \pm SEM. Differences between two groups were compared using a two-tailed $t$-test. All calculations were performed using the Prism version 7.04 (GraphPad Software, San Diego, CA). $P<0.05$ was considered statistically significant.

\section{Results}

TLR5 Activation by Flagellin Injection Protects $\mathrm{CCl}_{4}$ Induced Liver Fibrosis

In this part, we evaluate the role of TLR5 signaling in hepatotoxin-induced fibrotic livers in mice treated with or 
A

H\&E

Sirius-red
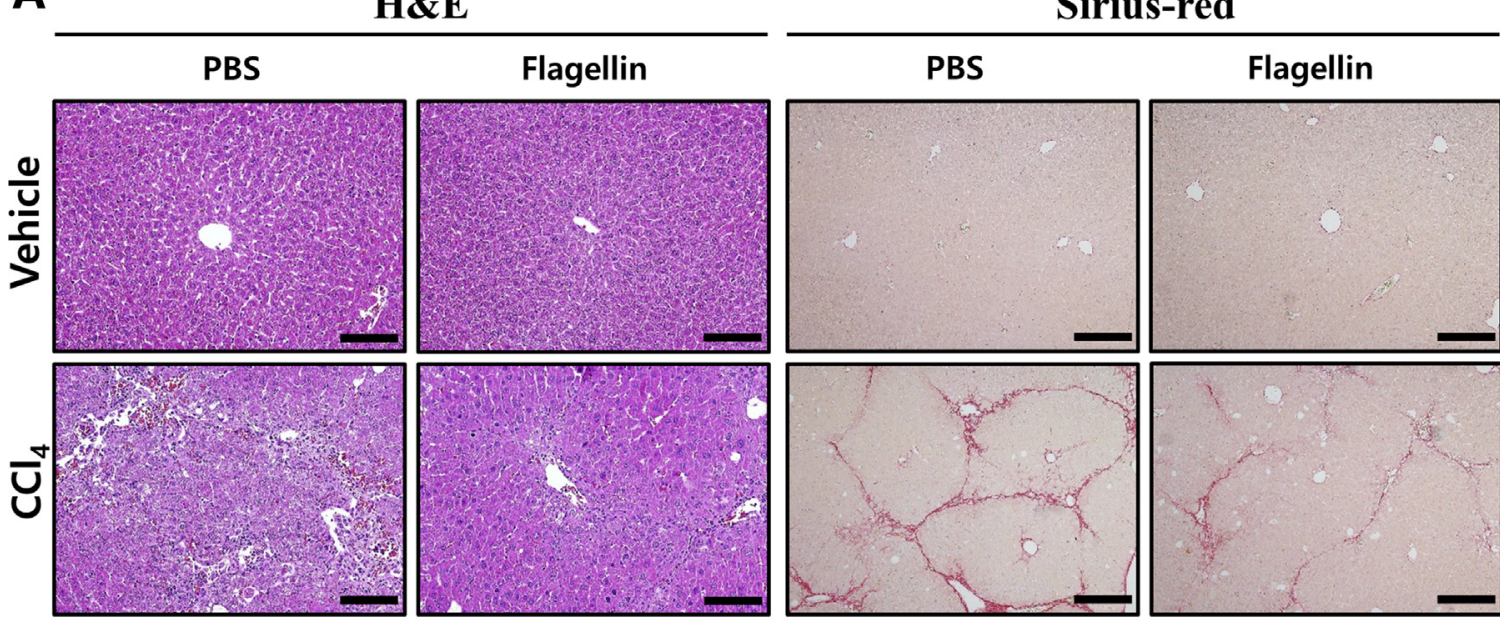

B
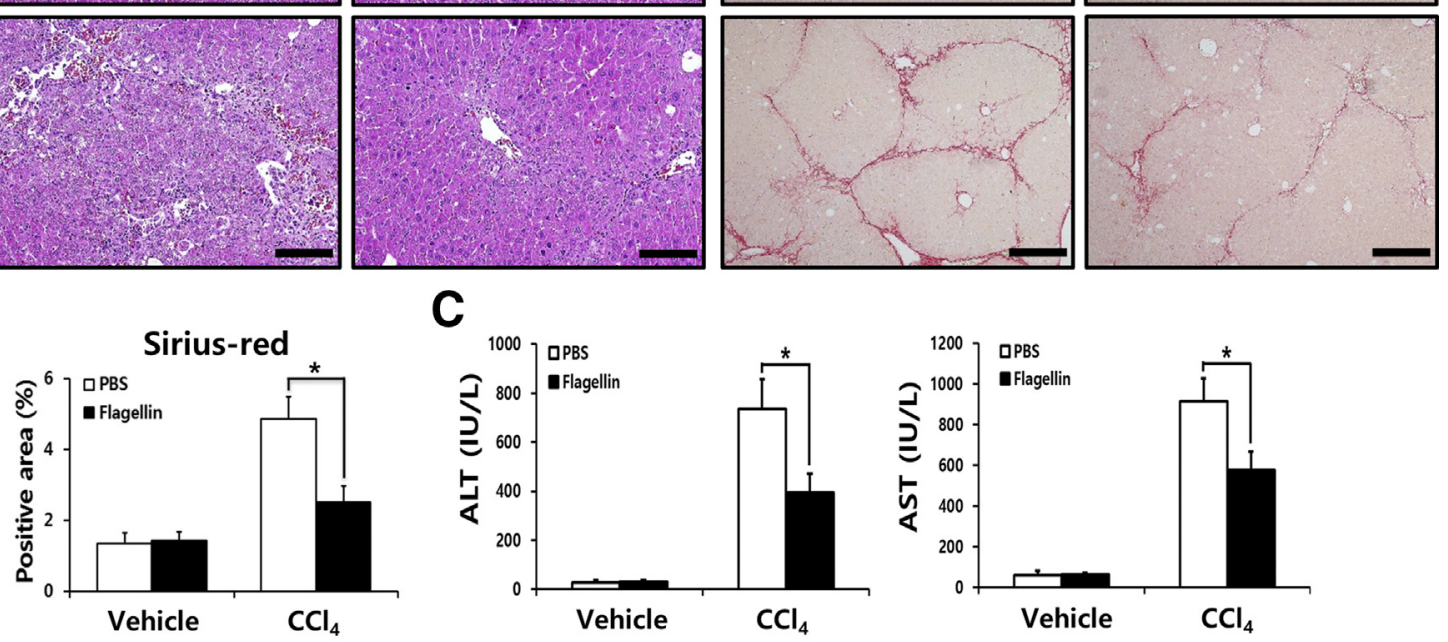

C
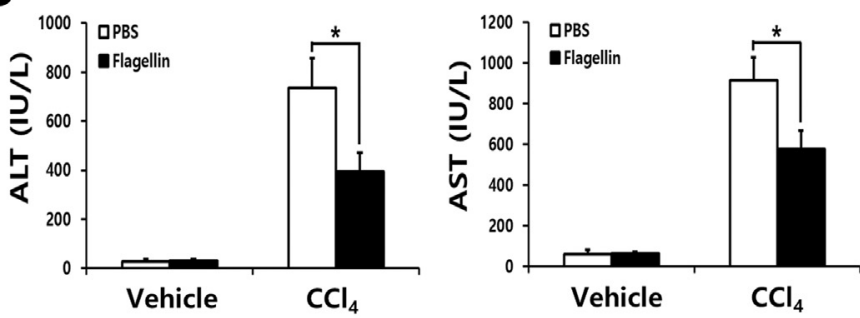

D
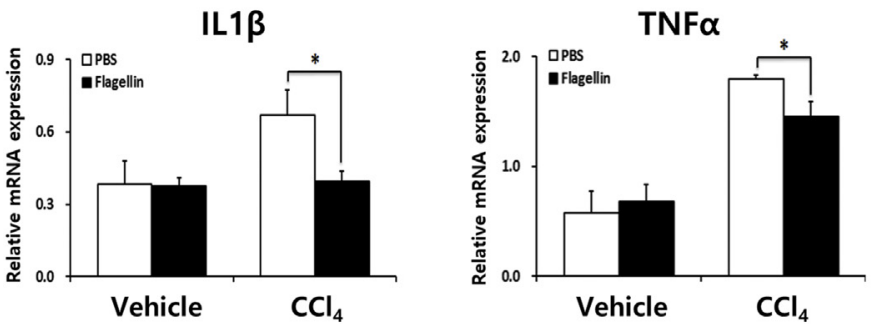

E
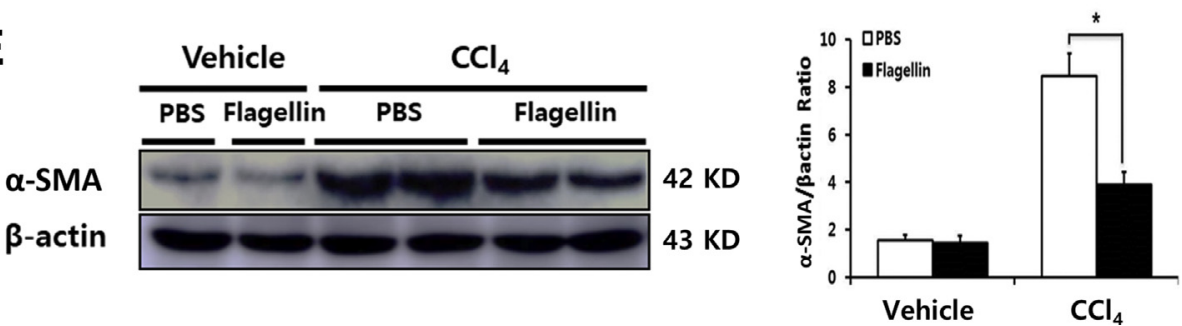

Figure 1 Toll-like receptor (TLR) 5 activation ameliorates hepatotoxin-induced liver fibrosis. Wild-type mice were injected with vehicle (corn oil) or carbon tetrachloride $\left(\mathrm{CCl}_{4}\right)(2 \mathrm{~mL} / \mathrm{kg}$ body weight) three times per week for 4 weeks. Meanwhile, these mice were intraperitoneally treated with flagellin $(1 \mu \mathrm{g}$ per mouse) or phosphate-buffered saline (PBS) every other day. A: Hematoxylin and eosin (H\&E) or Sirius red staining of liver tissues were performed to assess liver fibrosis. B: The percentage of fibrosis area was quantified. C: Serum levels of alanine aminotransferase (ALT) and aspartate aminotransferase (AST) were determined to assess the severity of chronic liver injury. D: mRNA expression of TNFA and ILIB was analyzed by quantitative real-time PCR. E: The protein level of $\alpha$-smooth muscle actin ( $\alpha$-SMA) was determined by Western blot analysis. Data are expressed as means \pm SEM per group. $n=6$ per group. ${ }^{*} P<0.05$ (twotailed $t$-test). Scale bars: $100 \mu \mathrm{m}$ (H\&E); $200 \mu \mathrm{m}$ (Sirius red). Original magnification: $\times 200(\mathrm{H} \& \mathrm{E}) ; \times 100$ (Sirius-red).

without flagellin. As indicated in Figure 1A, flagellin treatment ameliorated $\mathrm{CCl}_{4}$-induced liver damages and the associated liver fibrosis, as confirmed by histopathologic analysis and Sirius-red staining, respectively. In line with these findings, we found reduced percentage of
Sirius-red-positive area in injured livers of flagellin-treated mice (Figure 1B). In addition, significantly reduced liver damage was confirmed by lower levels of liver injury-associated serum biochemicals (Figure 1C). To further verify the effect of TLR5 signaling on inflammatory 
A

H\&E

Sirius-red
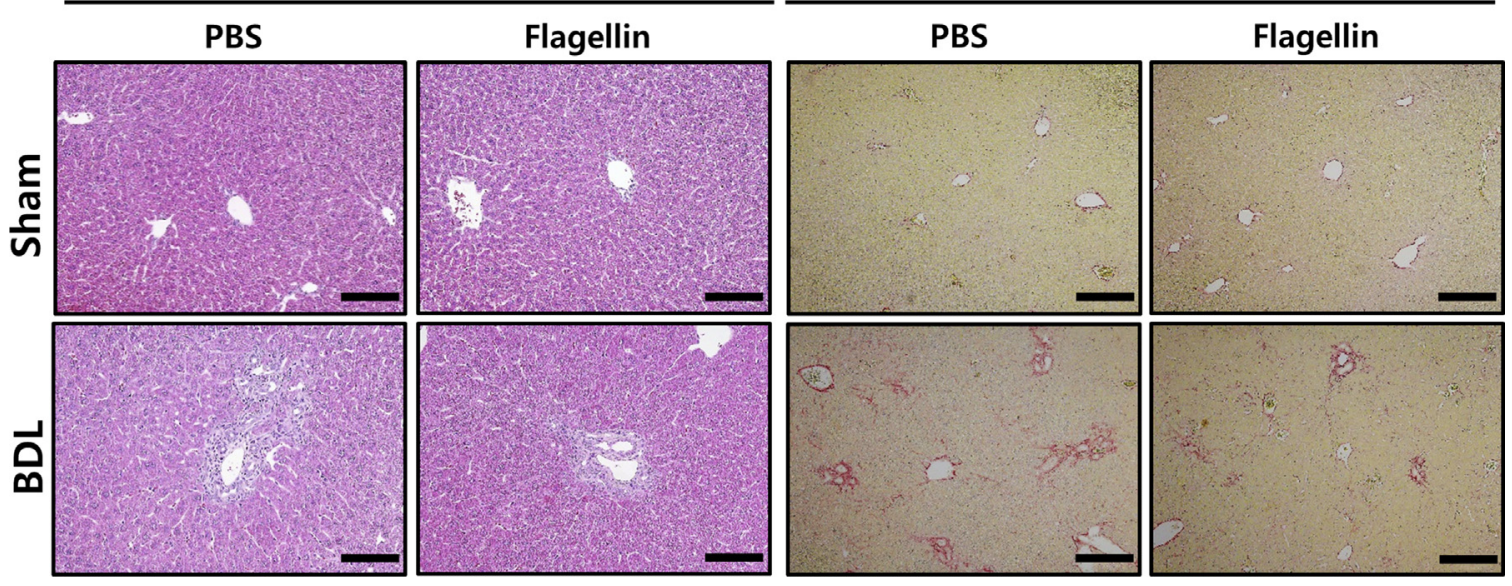

B
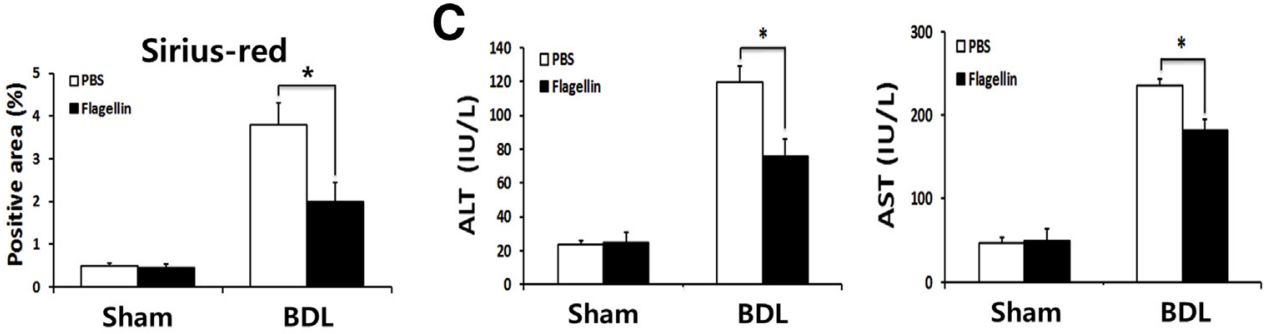

D
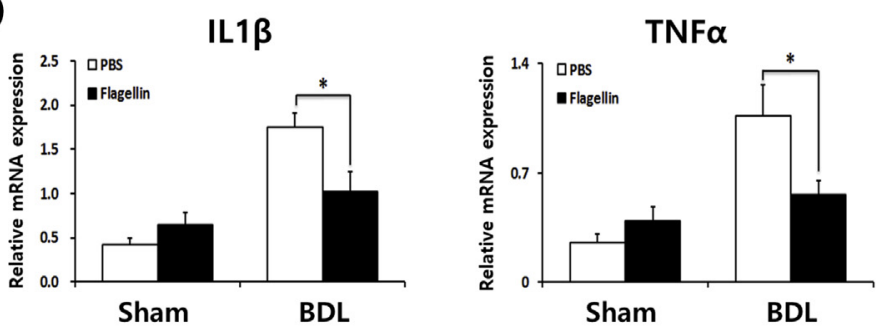

$\mathbf{E}$
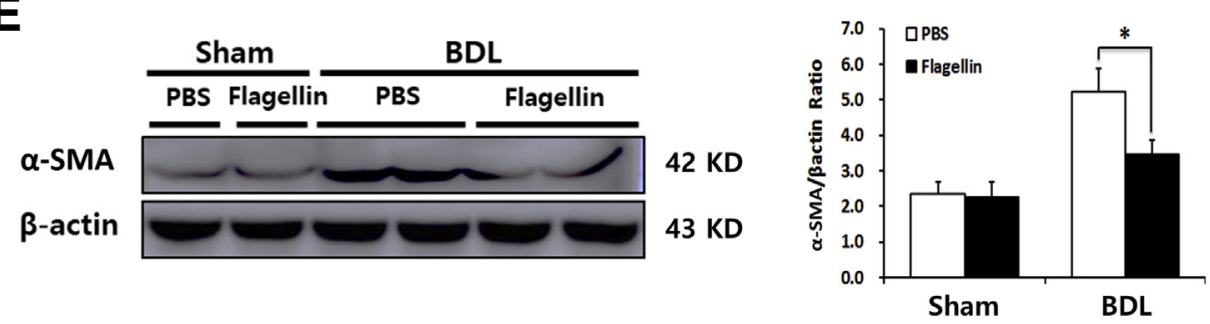

Figure 2 Stimulation of Toll-like receptor (TLR) 5 signaling with flagellin attenuates cholestasis-induced liver fibrosis. Wild-type mice were subjected to sham surgery or bile duct ligation (BDL). These mice were intraperitoneally injected with flagellin ( $1 \mu \mathrm{g}$ per mouse) or phosphate-buffered saline (PBS) every other day for 2 weeks. A: Liver sections were stained with hematoxylin and eosin (H\&E) or Sirius red to assess liver fibrosis. B: The percentage of fibrotic lesion was quantified. C: Serum levels of alanine aminotransferase (ALT) and aspartate aminotransferase (AST) were determined to assess the severity of chronic liver injury. D: mRNA expression of TNFA and IL1B were evaluated by quantitative real-time PCR. E: The protein level of $\alpha$-smooth muscle actin ( $\alpha$ SMA) was determined by Western blot analysis. Data are expressed as means \pm SEM per group. $n=5$ (sham surgery) and 8 (BDL) per group. ${ }^{\star} P<0.05$ (two-tailed $t$ test). Scale bars: $100 \mu \mathrm{m}$ (H\&E); $200 \mu \mathrm{m}$ (Sirius red). Original magnification: $\times 200$ (H\&E); $\times 100$ (Sirius red).

responses in injured livers, we assessed mRNA levels of proinflammatory genes and found significantly decreased expression levels of $I L 1 \beta$ and $T N F \alpha$ in the livers of $\mathrm{CCl}_{4^{-}}$ treated mice injected with flagellin (Figure 1D). In addition, reduced protein level of $\alpha$ SMA was observed in the livers of $\mathrm{CCl}_{4}$-treated mice injected with flagellin (Figure 1E). These results were further supported by lower expression levels of profibrogenic genes, such as $\alpha S M A$, Coll, TGFB, and $T I M P 1$, in fibrotic livers treated with flagellin (Supplemental Figure S1). These findings suggest that activation of TLR5 signaling can attenuate hepatotoxin-mediated chronic liver injury and its related fibroinflammatory responses in mice. 
A

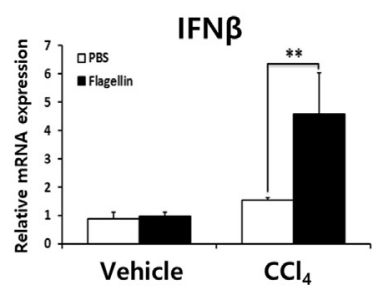

C

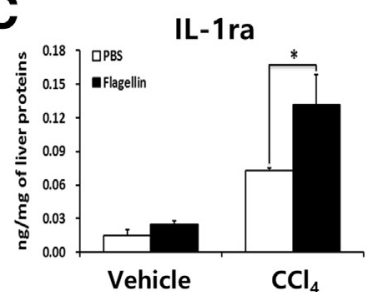

IFN $\beta$

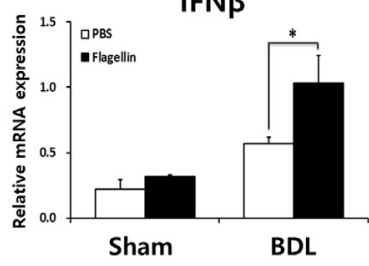

IL-1ra

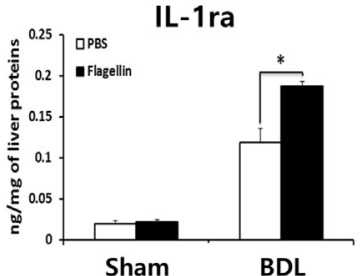

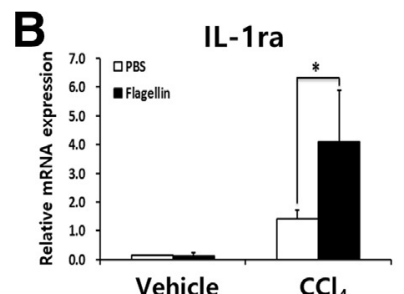

D

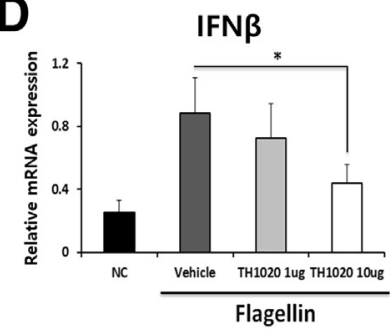

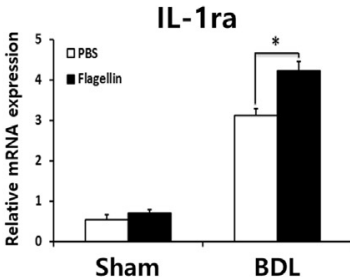

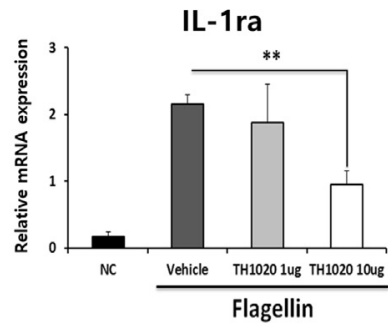

Figure 3 Expression levels of IFN $\beta$ and ILIRN increase by Toll-like receptor (TLR) 5 signaling pathway. A: The expression levels of IFN $\beta$ were measured in fibrotic livers by quantitative real-time PCR. The mRNA and protein levels of IL1RN were quantified in fibrotic livers as confirmed by quantitative real-time PCR (B) and enzyme-linked immunosorbent assay (C), respectively. D: Wild-type mice were intraperitoneally treated with TH1020 (a TLR5 antagonist; 1 or $10 \mu \mathrm{g}$ per mouse) or vehicle. After 30 minutes, these mice were intraperitoneally injected with flagellin ( $1 \mu \mathrm{g}$ per mouse). After 2 hours, the liver samples were collected, and mRNA expression of IFN $\beta$ and IL1RN was analyzed using quantitative real-time PCR. Mean values from three independent experiments are presented and samples were assayed in duplicate. Data are expressed as means \pm SEM per group. $n=4$ per group. ${ }^{*} P<0.05,{ }^{* *} P<0.01$ (two-tailed $t$-test).

\section{Activation of TLR5 Signaling Pathway Attenuates Cholestasis-Induced Liver Fibrosis}

To further clearly confirm the effects of TLR5 signaling on fibrotic responses, we next performed further experiments using cholestatic liver injury model, another wellestablished rodent model of liver fibrosis. ${ }^{18}$ Similar to the results from Figure 1, reduced liver damage and fibrotic responses in the livers of flagellin-treated mice subjected to BDL were confirmed by histopathologic analysis and Sirius-red staining (Figure 2A). Similar patterns were observed in the results of Sirius-red-positive area and levels of serum biochemical (Figure 2, B and C). Significant lower inflammation was also observed in the fibrotic livers of mice treated with flagellin compared with those of mice treated with PBS (Figure 2D). Furthermore, reduced protein level of $\alpha$-SMA was observed in the fibrotic livers of mice treated with flagellin (Figure 2E), which was consistent with the lower expression levels of profibrogenic genes in flagellin-treated fibrotic livers than those in PBS-treated fibrotic livers (Supplemental Figure S2). Contrary to a previous article as mentioned above, ${ }^{16}$ these findings, together with the results from Figure 1, strongly suggest that flagellin-mediated activation of TLR5 signaling can exert beneficial effects in mice with liver fibrosis.

\section{TLR5 Signaling Induces Production of Type I IFN-IL1RN Signaling Pathway}

As mentioned above, TLR5 signaling is transduced by two cascades of MyD88 or TRIF-mediated pathway, dependent on the status of TLR5 dimerization. ${ }^{8}$ Because NF- $\kappa \mathrm{B}$ or AP-1 signaling-mediated induction of proinflammatory cytokines, chemokines, and HSC activation promotes liver fibrosis, ${ }^{21}$ we assumed that the protective role of TLR5 signaling in liver fibrosis might be mediated by IFN $\beta$ production via TRIF-IRF3 signaling. On the basis of this notion, we evaluated whether flagellin treatment affects IFN $\beta$ mRNA expression in chronically injured livers. The results indicate that significantly increased expression levels of $I F N \beta$ by flagellin treatment were confirmed in livers of mice treated with $\mathrm{CCl}_{4}$ or subjected to $\mathrm{BDL}$ (Figure 3A). Given the fact that type 1 IFN exerts hepatoprotective effects via IL1RN production in fibrotic livers, ${ }^{18}$ we sought to assess whether TLR5-mediated protective effects on liver fibrosis are involved in the production of IL1RN. We found that the expression levels of ILIRN by flagellin treatment were significantly increased in the livers of mice treated with $\mathrm{CCl}_{4}$ or subjected to BDL (Figure 3B). In agreement with this finding, increased protein levels of IL1RN were observed in fibrotic livers of flagellin-treated mice (Figure 3C). To clearly ascertain the role of TLR5 signaling in the production of IFN $\beta$ and IL1RN, we used the TLR5 antagonist TH1020 to inhibit TLR5 signaling in livers. We initially determined the exact time point based on results indicating the most highly expressed ILIRN 2 hours after flagellin injection (Supplemental Figure S3A). Mice were treated with TH1020 30 minutes before flagellin injection, and then hepatic expression levels of IFN $\beta$ and ILIRN were evaluated 2 hours later. The results indicate that treatment of TH1020 successfully inhibited flagellin-mediated production of $I F N \beta$ and ILIRN in livers (Figure 3D), providing that flagellin-mediated TLR5 signaling might play a pivotal role in reducing the severity of hepatic fibrogenesis through the IFN $\beta$-IL1RN axis. 


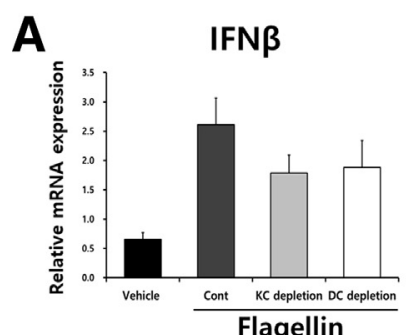

D

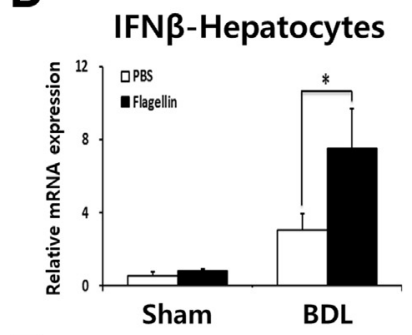

$\mathbf{E}$

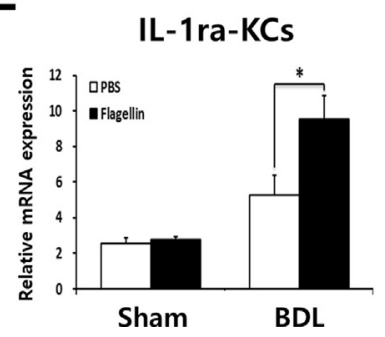

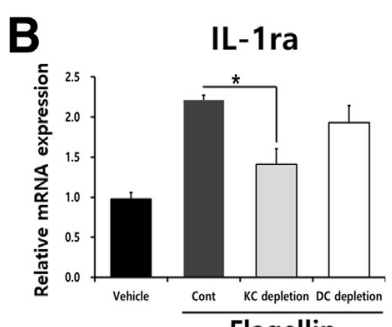

Flagellin

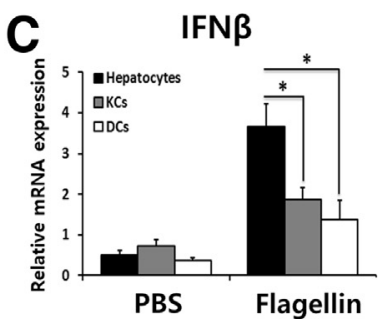

PBS
Flagellin
IL-1 ra

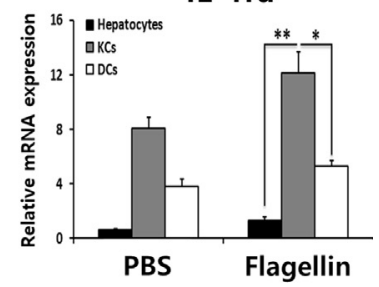

Figure $4 \quad I F N \beta$ and IL1RN are mainly derived from hepatocytes and Kupffer cells (KCS), respectively. Dendritic cell (DC) depletion in CD11C diphtheria toxin receptor transgenic (CD11C-DTRtg) mice was induced by diphtheria toxin (DT) injections ( $4 \mathrm{ng} / \mathrm{g}$ of body weight) for 2 consecutive days, and clodronate liposome injections ( $200 \mu \mathrm{L}$ per mouse) for 2 consecutive days were used to deplete $\mathrm{KCs}$. A: Hepatic mRNA expression levels of IFN $\beta$ were evaluated by using quantitative real-time PCR. B: Hepatic mRNA expression levels of $I L 1 R N$ were evaluated by using quantitative real-time PCR. C: The expression levels of IFN $\beta$ and IL1RN in the hepatocytes, DCs, and KCs isolated from livers of mice after 2 hours of flagellin injection were evaluated by using quantitative real-time PCR. D: The mRNA expression of IFN $\beta$ in hepatocytes isolated from livers of mice subjected to sham or bile duct ligation (BDL) are markedly increased by flagellin. E: The pattern of IL1RN expression level is similar in KCs isolated from the livers of mice subjected to sham surgery or BDL. Mean values from three independent experiments are presented and samples were assayed in duplicate. Data are expressed as means \pm SEM per group. $n=$ 3. ${ }^{*} P<0.05,{ }^{* *} P<0.01$ (two-tailed $t$-test).

\section{IFN $\beta$ and IL1RN Are Derived from Different Cellular Source in the Liver}

To explore the more precise mechanism of the protective role of TLR5 signaling, we ascertained the cellular source of TLR5 in the liver. TLR5 mRNA expression levels in several cell types isolated from WT healthy livers showed that hepatocytes are the major cellular source of TLR5 in the liver (Supplemental Figure S3B). This result was consistent with recent published findings of significantly higher expression levels of TLR5 in hepatic parenchymal cells than NPCs. ${ }^{13}$ To demonstrate flagellin-mediated TLR5 activation and consequent induction of IFN $\beta$, we administered flagellin to WT mice and KC- and DC-depleted mice. Similar expression levels of hepatic IFN $\beta$ were observed 2 hours after flagellin injection despite the DC- or KCdepleted condition (Figure 4A), indicating that TLR5 signaling-mediated IFN $\beta$ expression was predominantly induced in hepatocytes. Interestingly, expression levels of hepatic ILIRN were significantly increased 2 hours after flagellin injection (Supplemental Figure S3A), and such effects were markedly decreased in the livers of $\mathrm{KC}$ depleted mice (Figure 4B), providing that the main IL1RN-producing cells are KCs rather than hepatocytes or DCs. To further support these results, we isolated hepatocytes, KCs, and DCs from livers 2 hours after flagellin injection. As shown in Figure $4 \mathrm{C}$, the highest expression levels of IFN $\beta$ and ILIRN by flagellin injection were observed in hepatocytes and KCs, respectively. In accordance with these findings, the expression levels of IFN $\beta$ in hepatocytes isolated from fibrotic livers injected with flagellin were significantly higher than those in hepatocytes isolated from the livers of PBS-treated mice with fibrosis (Figure 4D). In addition, the expression levels of ILIRN were markedly up-regulated in $\mathrm{KCs}$ isolated from the fibrotic livers injected with flagellin (Figure 4E). Taken together, these findings indicate that hepatocytes are the predominant cellular source of TLR5 and its target gene, $I F N \beta$, induced by flagellin treatment. Combined with previous reports on the IFN $\beta$-IL1RN axis, ${ }^{18,22}$ our results indicate that increased expression of IL1RN in flagellininjected livers might be affected by increased TLR5 signaling-mediated IFN $\beta$ expression.

Deficiency of Type I IFN Signaling Results in the Increase of Severity of Cholestasis-Induced Liver Injury after Flagellin Treatment

Because activation of TLR5 signaling is involved in the production of IFN $\beta$, which in turn induces IL1RN production, we next verify whether the protective effects of flagellin on liver fibrosis are mediated by type 1 IFN signaling, using IFNAR1 KO mice. To evaluate the role of 
A H\&E-BDL
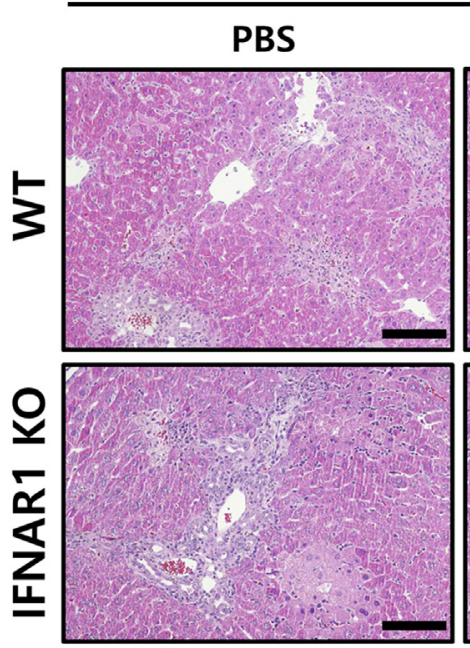

B

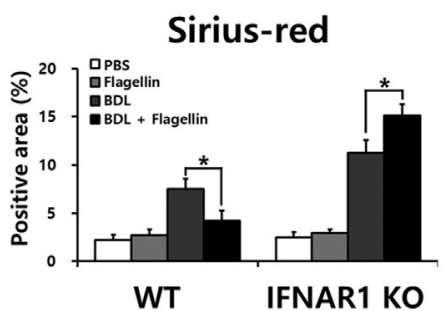

IL1 $\beta$

D

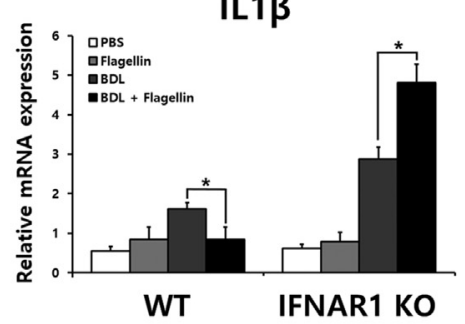

C

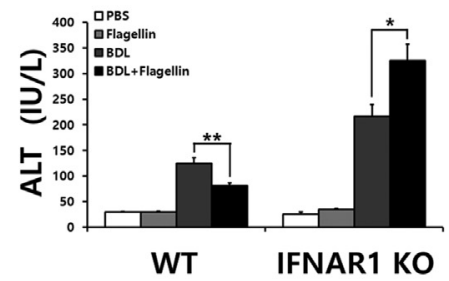

TNF $\alpha$

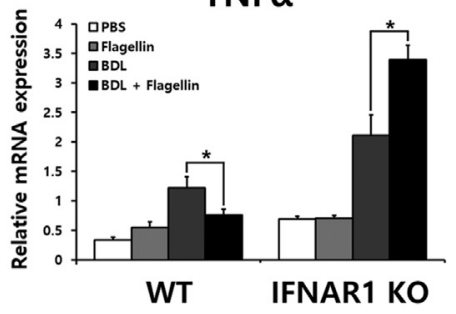

IFNAR1 KO

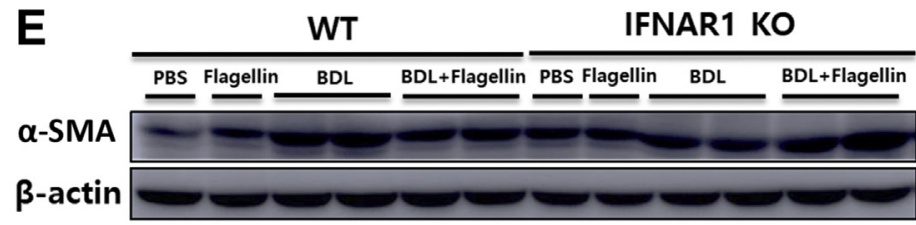

42 KD

43 KD
Sirius-red-BDL
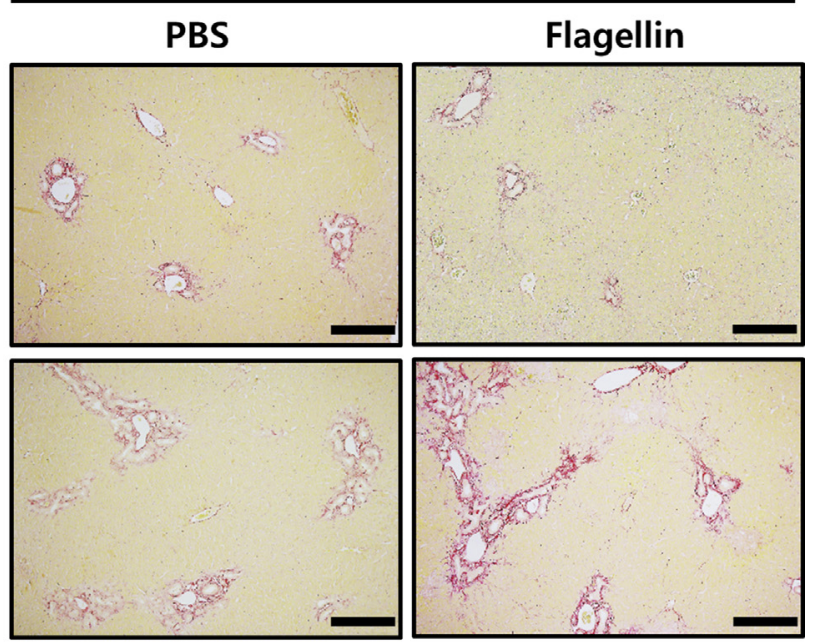
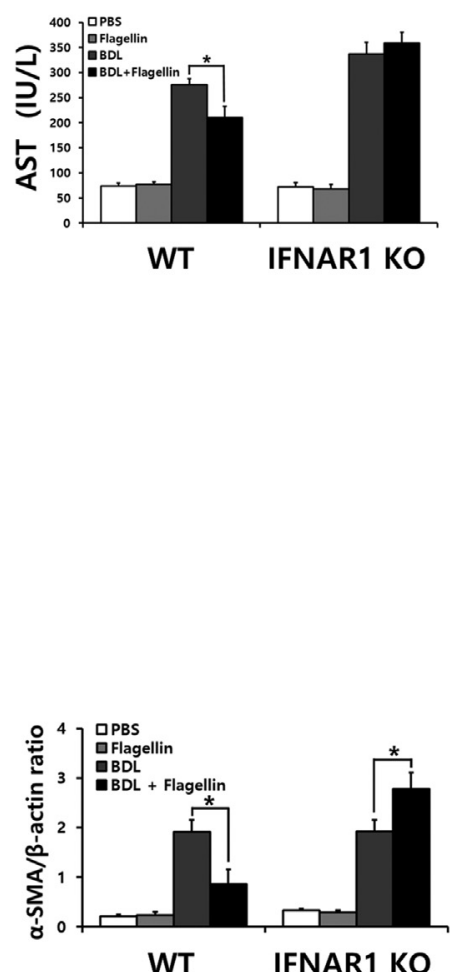

Figure 5 Flagellin-mediated Toll-like receptor (TLR) 5 signaling exacerbates the severity of liver fibrosis in the absence of type 1 interferon (IFN) signaling. Wild-type (WT) or interferon IFN- $\alpha / \beta$ receptor 1 (IFNAR1) knockout (K0) mice were subjected to sham surgery or bile duct ligation (BDL). These mice were intraperitoneally injected with flagellin $(1 \mu \mathrm{g}$ per mouse) or phosphate-buffered saline (PBS) every other day for 2 weeks. A: Liver sections were stained with hematoxylin and eosin (H\&E) or Sirius red to assess liver fibrosis. B: The percentage of fibrotic lesion was quantified. C: Serum levels of alanine aminotransferase (ALT) and aspartate aminotransferase (AST) were determined to evaluate chronic liver injury. D: Hepatic mRNA levels of TNFA and IL1B were analyzed by quantitative real-time PCR. E: Protein level of $\alpha$-smooth muscle actin ( $\alpha$ SMA) was determined by Western blot analysis. Mean values from three independent experiments are presented and samples were assayed in duplicate. Data are expressed as means \pm SEM per group. $n=5$ (sham surgery) and 8 (BDL) per group. ${ }^{*} P<0.05$ (two-tailed $t$-test). Scale bars: $100 \mu \mathrm{m}$ (H\&E); $200 \mu \mathrm{m}$ (Sirius red). Original magnification: $\times 200$ (H\&E); $\times 100($ Sirius red).

flagellin on the severity of liver fibrosis in WT or IFNAR1 KO mice, we assessed histopathologic examination through H\&E or Sirius-red staining. Similar histopathologic features were observed in the sham surgery group of
WT or IFNAR1 KO mice (Supplemental Figure S4A). Consistent with previous published findings of the protective role of type 1 IFN in liver fibrosis, ${ }^{18}$ the severity of cholestasis-induced liver fibrosis in IFNAR1 KO mice was 

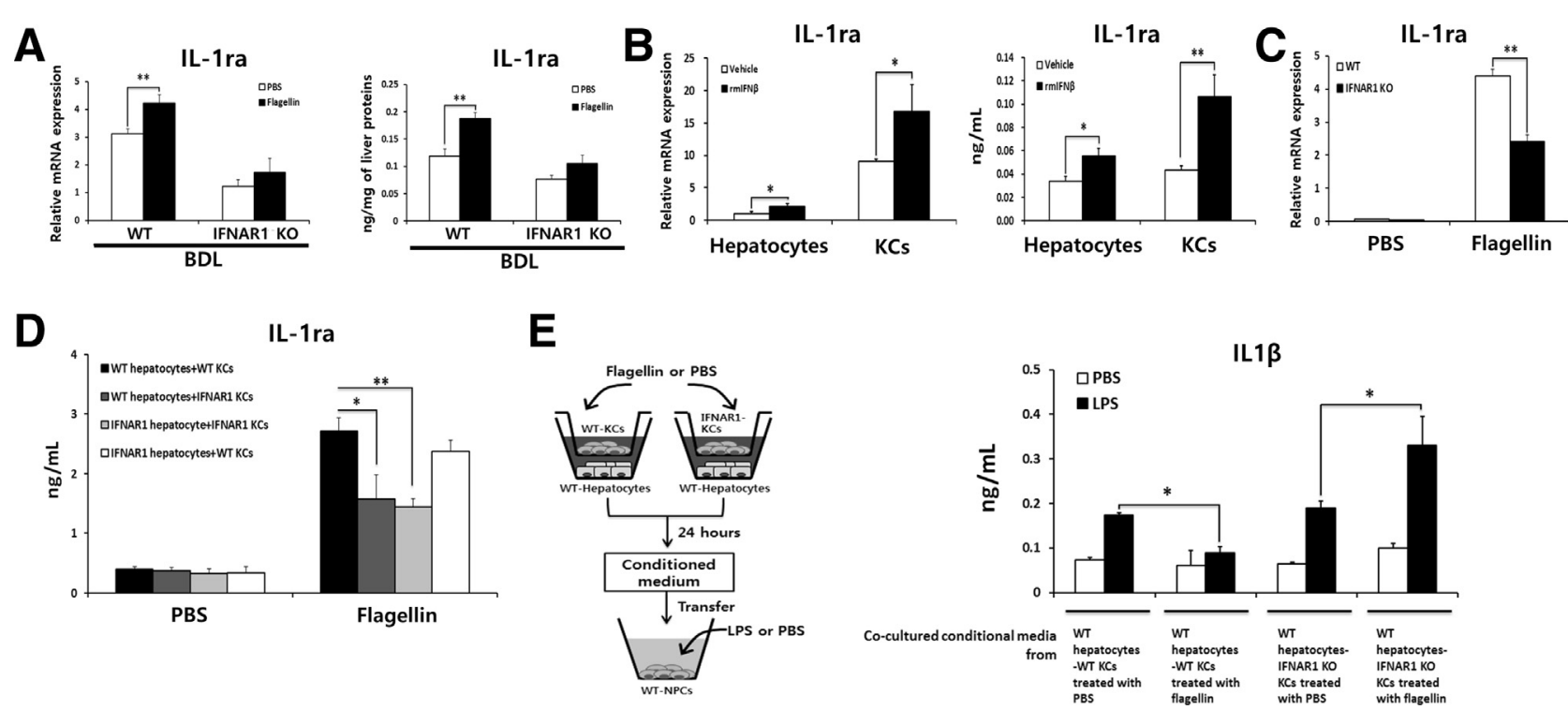

Figure 6 Type 1 interferon (IFN) signaling is indispensable for the protective effects of flagellin on cholestasis-induced liver injury. A: Hepatic mRNA expression and protein levels of IL-1 receptor antagonist (IL1RN) were measured by using quantitative real-time PCR and enzyme-linked immunosorbent assay (ELISA), respectively. B: Hepatocytes and Kupffer cells (KCs) isolated from wild-type (WT) mice were stimulated with recombinant murine IFN $\beta$ (500 IU/mL), and mRNA levels of IL1RN in both cell types and protein levels of IL1RN in culture supernatants were measured. C: WT or IFNAR1 knockout (K0) mice were intraperitoneally treated with flagellin $(1 \mu \mathrm{g}$ per mouse) or phosphate-buffered saline (PBS). After 2 hours of flagellin injection, mRNA expression of IL1RN in livers was measured by quantitative real-time PCR. D: Primary WT or IFNAR1 K0 hepatocytes were co-cultured with WT or IFNAR1 K0 KCs treated with 100 ng/ $\mathrm{mL}$ of flagellin or PBS for 24 hours. Cell supernatants were collected for measuring protein levels of IL1RN using ELISA or using further experiments. E: These supernatants (conditioned medium) were transferred to WT nonparenchymal cell (NPCs) treated with lipopolysaccharide (LPS) (1 $\mu \mathrm{g} / \mathrm{mL})$ or PBS for 24 hours. The protein concentrations of IL1 $\beta$ in supernatants were measured by using ELISA. Mean values from three independent experiments are presented and samples were assayed in duplicate. Data are expressed as means \pm SEM per group. $n=8$ (A); $n=6$ (B-E). ${ }^{*} P<0.05,{ }^{* *} P<0.01$ (two-tailed $t$-test).

higher than those in WT mice (Figure 5A). Interestingly, the susceptibility of hepatic fibrosis was significantly more increased by flagellin treatment in IFNAR1 KO mice, contrary to the pattern in WT mice, as demonstrated by histopathologic examination (Figure 5A). Similar results were observed in measuring the percentage of Siriusred-positive area (Figure 5B). In addition, cholestasisinduced liver injury in IFNAR1 KO mice treated with flagellin was markedly higher than those in PBS-treated IFNAR1 KO mice, as confirmed by increased serum levels of alanine aminotransferase but not aspartate aminotransferase (Figure 5C). IFNAR1 KO mice treated with flagellin also had significantly increased hepatic inflammation compared with IFNAR1 KO mice without treatment of flagellin in fibrotic milieu (Figure 5D). In line with the above findings shown in Figures 1 and 2, significantly lower expression levels of profibrogenic genes were observed in the liver of flagellin-treated WT mice, while conversely the expression levels of TIMP1, Coll, and $\alpha S M A$ were increased by flagellin injection in fibrotic livers of IFNAR1 KO mice (Supplemental Figure S4B). Similar patterns were observed in the protein level of $\alpha \mathrm{SMA}$, as confirmed by Western blot analysis (Figure 5E), indicating that flagellin exerts proinflammatory and profibrogenic effects in livers without type 1 IFN signaling. Collectively, these results indicate that the antifibrogenic activities of flagellin in livers are dependent on type 1 IFN signaling.

\section{Type I IFN Signaling Is Essential for the Beneficial Effects of Flagellin on Liver Fibrosis}

These above-mentioned findings prompted us to test the reason why treatment of flagellin produced different outcomes, depending on the presence of type 1 IFN signaling, in injured liver. For this reason, we evaluated whether flagellin differentially regulates hepatic IL1RN production based on type 1 IFN signaling in the livers of mice subjected to BDL. As shown in Figure 6A, hepatic mRNA or protein levels of IL1RN were significantly increased in the fibrotic livers of mice treated with flagellin, whereas such effects were abrogated in the fibrotic livers of IFNAR1 KO mice. These results were further supported by in vitro experiments that found that mRNA or protein levels of IL1RN were markedly elevated in recombinant murine IFN $\beta$-treated hepatocytes or KCs isolated from WT mice (Figure 6B). Furthermore, the expression levels of ILIRN induced by flagellin were markedly reduced in the livers of IFNAR1 KO mice compared with those of WT mice (Figure 6C). These results indicate that flagellin-mediated IFN $\beta$ production is essential for subsequent IL1RN production. For clarification of the underlying mechanism, we first performed in vitro experiments using a co-culture system of hepatocytes and KCs isolated from WT or IFNAR1 KO mice. The results indicate that the production of IL1RN by flagellin was significantly decreased in the co-cultured media of IFNAR1-deficient condition in KCs, regardless 

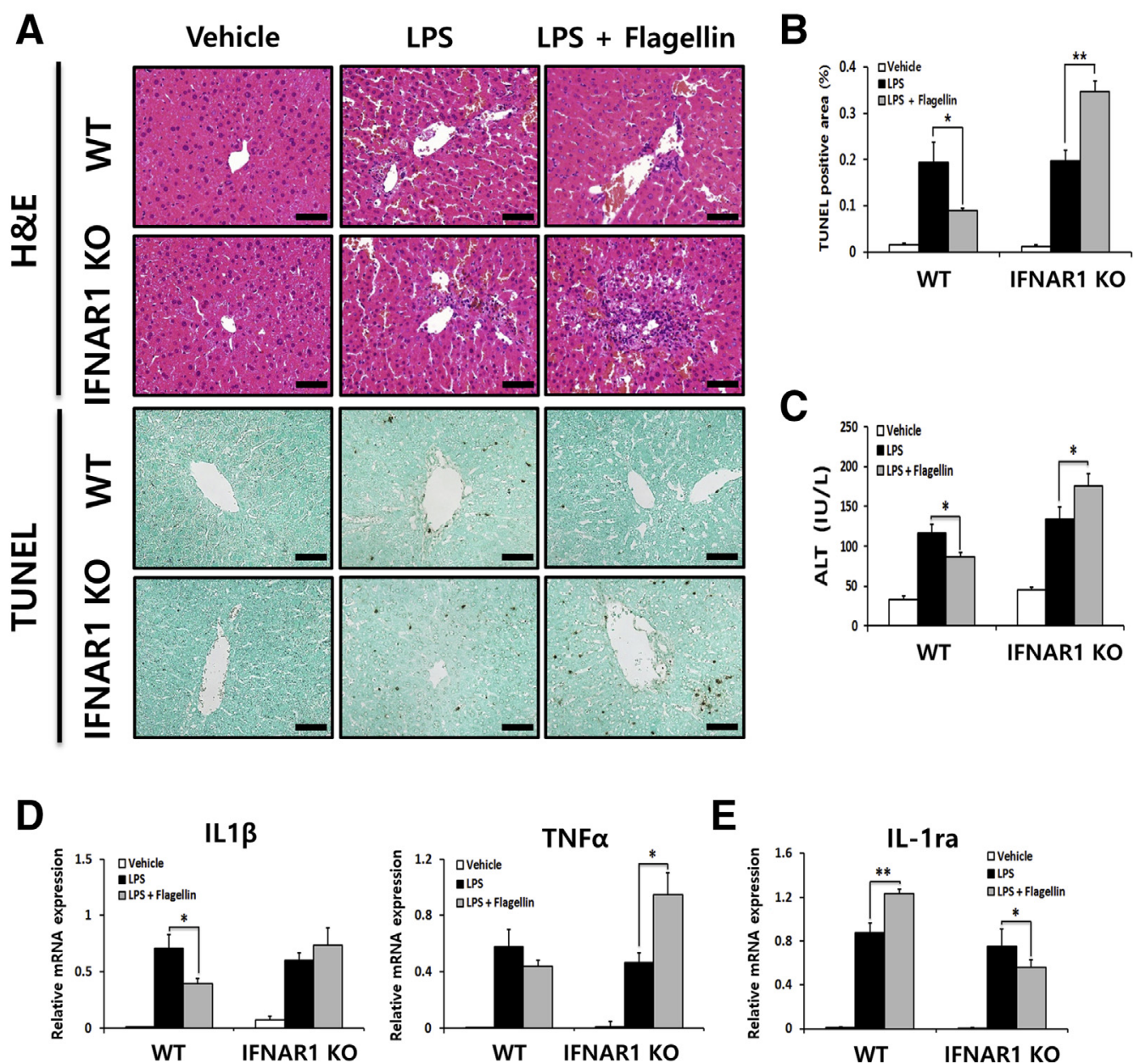

Figure 7 Flagellin-mediated Toll-like receptor (TLR) 5 signaling increases the severity of lipopolysaccharide (LPS)-induced acute liver injury (ALI) in the absence of type 1 interferon (IFN) signaling. After flagellin injection ( $1 \mu \mathrm{g}$ per mouse), wild-type (WT) or IFN- $\alpha / \beta$ receptor 1 (IFNAR1) knockout (K0) mice were administered with LPS ( $20 \mathrm{mg} / \mathrm{kg}$ body weight) to induce ALI. After 6 hours of LPS injection, the mice were sacrificed, and samples were collected for further experiments. A: Hematoxylin and eosin (H\&E) or terminal deoxynucleotidyl transferase-mediated dUTP nick-end labeling (TUNEL) staining of liver tissues were performed to assess ALI. B: The quantification of the TUNEL-positive cells. C: Serum alanine aminotransferase (ALT) levels were determined to evaluate the severity of ALI. Hepatic expression levels of IL1B (D), TNFA, and IL1RN (E) were evaluated by quantitative real-time PCR. Data are expressed as means \pm SEM per group. $n=8$ per group. ${ }^{*} P<0.05,{ }^{* *} P<0.01$ (two-tailed $t$-test). Scale bars $=50 \mu$ m. Original magnification, $\times 400$.

of the presence of type 1 IFN signaling in hepatocytes (Figure 6D). In contrast, treatment of flagellin significantly increased the production of IL1RN in co-cultured media of IFNAR1-sufficient condition in $\mathrm{KCs}$, regardless of the presence of type 1 IFN signaling in hepatocytes. Although treatment of recombinant murine IFN $\beta$ directly increased the production of IL1RN in hepatocytes (Figure 6B), the results of these co-culture experiments indicate that IFN $\beta$ induced by flagellin affects $\mathrm{KCs}$, not hepatocytes, to produce anti-inflammatory and antifibrotic IL1RN. These results were consistent with our results (Figure 4) and previous findings ${ }^{18}$ that type 1 IFN signaling-mediated IL1RN production predominantly occurs in KCs. Interestingly, the expression levels of ILIRN induced by flagellin were still increased in the livers of IFNAR-deficient mice (Figure 6, C and D), indicating that flagellin-mediated IL1RN production is mediated by type 1 IFN signaling in a dependent or independent manner. On the basis of these findings together with our in vivo results (Figure 5), we hypothesized that flagellin might act as a proinflammatory mediator in the absence of type 1 IFN signaling because of the lower production of IL1RN when compared with the presence of type 1 IFN signaling. Thus, we performed additional experiments to clarify this notion. NPCs isolated from WT mice were treated with conditioned media, followed by LPS treatment to induce inflammatory responses. As shown in Figure 6E, flagellin-treated conditioned media co-cultured with WT hepatocytes and WT KCs significantly decreased LPS-induced inflammation, as confirmed by reduced protein levels of IL $1 \beta$, whereas IL $1 \beta$ levels were conversely increased by treatment of flagellin-treated conditioned media co-cultured with WT hepatocytes and IFNAR1 KO KCs.

To elucidate the differential modulation of flagellin on IL1RN production and hepatic inflammation, we further evaluated whether the in vivo condition could reproduce 
these in vitro results. As shown in Figure 7A, flagellinadministered mice had reduced severity of LPS-induced ALI concomitant with decreased infiltration of inflammatory cells. Consistent with the in vitro findings (Figure 6, D and E), IFNAR1 KO mice treated with flagellin had significantly increased LPS-induced infiltration of inflammatory cells and hepatocellular death, as confirmed by $\mathrm{H} \& \mathrm{E}$ and TUNEL staining, respectively (Figure 7A). Similar patterns were observed in measuring the TUNEL-positive area and the levels of serum alanine aminotransferase

A
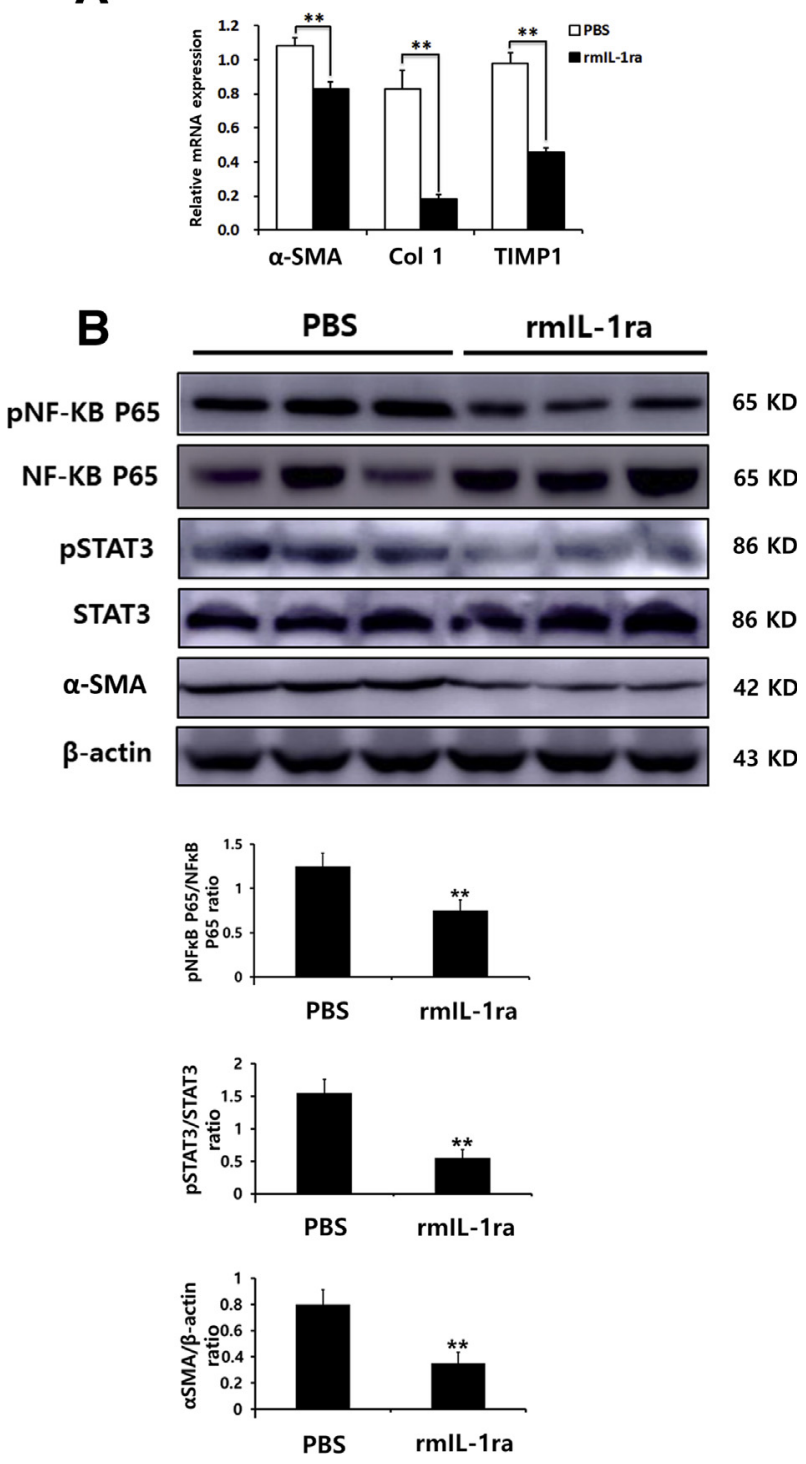

C

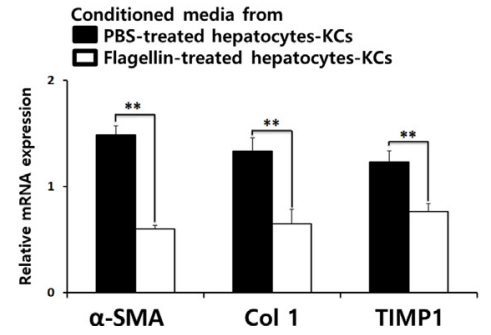

(Figure 7, B and C). Reduced inflammation was also observed in the injured livers of WT mice treated with flagellin, as confirmed by the lower expression levels of ILI $\beta$ (Figure 7D). Conversely, the expression levels of $T N F A$ were significantly increased in the injured livers of IFNAR1 KO mice treated with flagellin (Figure 7D). In addition, markedly increased $I L I R N$ expression by flagellin was observed in the injured livers of WT mice, whereas such effects were reversed in the injured livers of IFNAR1 KO mice (Figure 7E). Taken together, these in vitro and in vivo results strongly support our hypothesis and indicate that flagellin-mediated IL1RN production is not enough to overcome inflammation in IFNAR1-deficient milieu.

\section{IL1RN Attenuates HSC Activation and Its Related Fibrogenic Responses}

Because the activation of HSCs is one of the main triggers of hepatic fibrosis, ${ }^{23}$ we next assessed the therapeutic potential of IL1RN on HSC activation and fibrogenic responses. As shown in Figure 8A, significantly lower fibrogenesis in activated HSCs (day 7 after isolation) was observed by treatment of recombined murine IL1RN, as confirmed by the reduced expression levels of fibrogenic genes, including $\alpha S M A$, Coll, and TIMP1. Furthermore, significantly decreased activation (phosphorylation) of phospho-NF- $\kappa$ B p65 and STAT3, the key markers of HSC activation, ${ }^{24,25}$ and decreased $\alpha$-SMA protein level were observed in activated HSCs by the treatment of recombined murine IL1RN (Figure 8B). Consistent with these findings, the expression levels of these fibrogenic genes were also markedly reduced in activated HSCs treated with the abovementioned conditioned media (Figure 8C). Collectively, these results indicate that flagellin-mediated IL1RN has antifibrogenic activities by reducing HSC activation as well as anti-inflammatory activities.

\section{Discussion}

Recently, there has been increased awareness of the importance of pattern recognition receptors, including

\footnotetext{
Figure 8 Fibrogenic responses in activated hepatic stellate cells (HSCs) are reduced by treatment of IL-1 receptor antagonist (IL1RN). Activated HSCs were treated with recombined murine IL1RN $(10 \mathrm{ng} / \mathrm{mL})$ or PBS for 24 hours. A: The expression levels of $\alpha$ SMA, Col1, and TIMP1 in activated HSCs were analyzed by using quantitative real-time PCR. B: The protein levels of

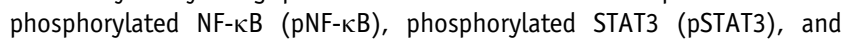
aSMA in activated HSCs were measured by Western blot analysis. C: Primary wild-type hepatocytes were co-cultured with WT-Kuppfer cells (KCs) stimulated with flagellin $(100 \mathrm{ng} / \mathrm{mL}$ ) or phosphate-buffered saline (PBS) for 24 hours. Cell supernatants were collected and treated on activated HSCs for 24 hours. The expression levels of $\alpha$ SMA, Col1, and TIMP1 were determined by using quantitative real-time PCR. Mean values from three independent experiments are presented and samples were assayed in duplicate. Data are expressed as means \pm SEM per group. $n=6$ per group. ${ }^{*} P<0.01$ versus PBS (two-tailed $t$-test).
} 


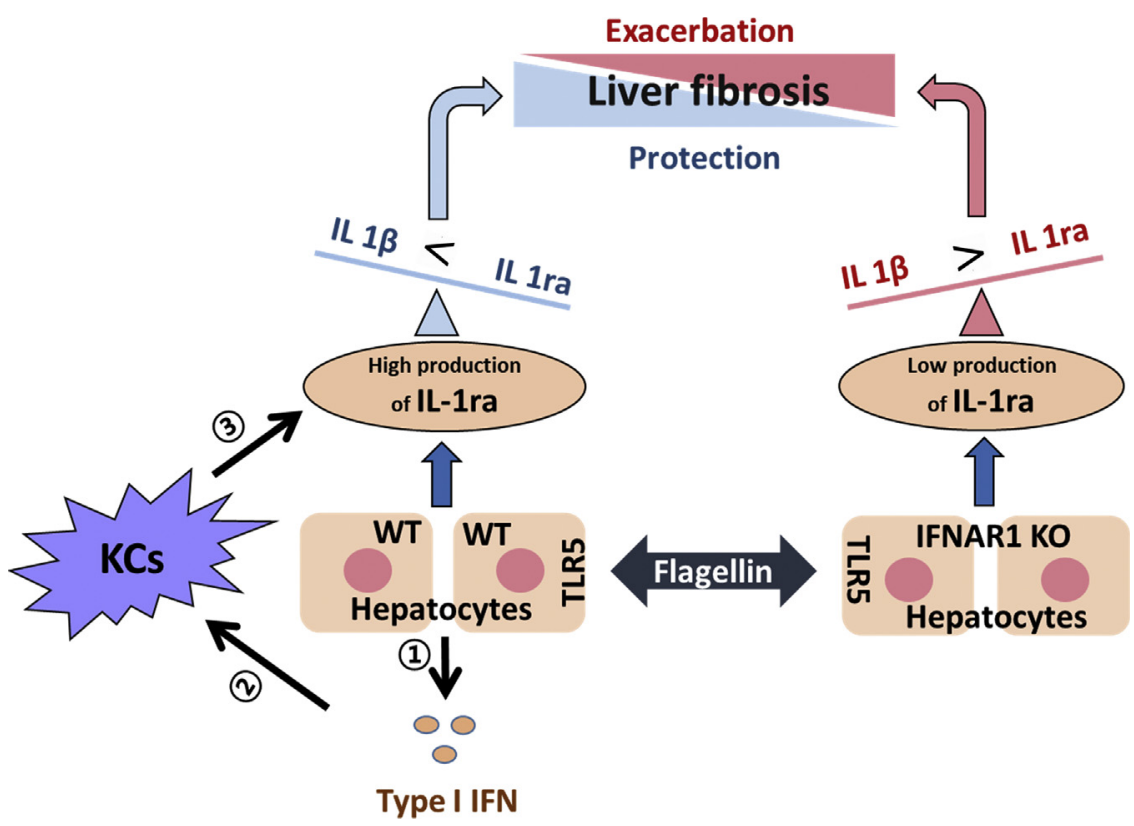

Figure 9 Schematic presentation showing that Toll-like receptor (TLR) 5 signaling ameliorates liver fibrosis by inducing interferon (IFN) $\beta-$ modulated IL-1 receptor antagonist (IL1RN) in mice. Flagellin stimulation can directly promote IL1RN production in hepatocytes and indirectly affect IL1RN production in Kuppfer cells (KCs) in a type 1 IFN-dependent manner. In addition to the known stimulation of the IL1RN production in hepatocytes by flagellin, activation of TLR5 signaling with flagellin predominantly occurred in wild-type (WT) hepatocytes, leading to type 1 IFN production, which in turn induces a high level of anti-inflammatory and antifibrogenic IL1RN in WT$\mathrm{KCS}$ (1, 2, and 3 pathway; black arrows). Even though increased IL1RN production is observed in IFNAR1 knockout (K0) mice on flagellin-mediated TLR5 activation, IL1RN levels are not enough to exert anti-inflammatory and antifibrogenic activities without type 1 IFN signaling. Therefore, manipulation of the TLR5 type 1 IFN-IL1RN axis may pave the way for providing a new therapeutic strategy for the treatment of liver fibrosis.
TLRs, because of their recognition capacity of tissue injury through binding damaged-associated molecular patterns in noninfectious condition as well as pathogen-associated molecular patterns in infectious condition. Hence, the interaction between TLRs and their endogenous ligands plays critical roles in wound healing responses and organ fibrosis, including liver fibrosis. ${ }^{22}$ In line with this notion, mounting evidence has indicated that the genetic manipulation of TLRs, including TLR4 and 9, was involved in the pathogenesis of liver fibrosis. ${ }^{26-28}$ More recently, it has been well documented that chronic liver diseases are closely associated with the gut-liver axis because intestinal permeability is increased by alteration of the intestinal epithelial tight junction. ${ }^{29,30}$ In addition, dysbiosis, defined as qualitative and quantitative changes in intestinal microbiota leading to microbial imbalance, is involved in the pathogenesis of hepatic injury, fibrosis, and related complications. ${ }^{30}$ Therefore, the possibility of recognition against hepatotoxic bacterial components might be increased gradually as liver diseases progresses because of systemic circulation of bacterial components via increased intestinal permeability. Indeed, intestinally derived bacterial components, such as LPS and DNA, are translocated and recognized by hepatic cells, including HSCs, which results in promoting hepatic fibrogenic responses. ${ }^{31,32}$ In contrast to these results, we have recently demonstrated the antifibrogenic TLR7 signaling pathway via type I IFN-mediated IL1RN production in response to bacterial or necrotic cell-derived RNA. ${ }^{18}$

Flagellin is a structural component of the flagellum in gram-negative bacteria and recognized by TLR5, which is highly expressed in various immune cells, such as macrophage and dendritic cells. ${ }^{8}$ Because liver is the main target tissue of translocated bacterial components, TLR5 signaling by recognizing flagellin in liver might be closely associated with the progression of liver fibrosis. However, the role of TLR5 is not fully understood because TLR5 KO mice could not mimic the exact pathological condition of liver fibrosis, as mentioned above. In addition, TLR5 signaling in hepatocytes protects high-fat diet-induced liver disease through promoting flagellated bacterial clearance. ${ }^{13}$ On the basis of these findings and in light of the clearly uncharacterized role of TLR5 in liver fibrosis, we herein endeavored to demonstrate the role of TLR5 signaling in the progression of liver fibrosis. The previous study found that overactivation of TLR5 signaling by high-dose flagellin (100 or $200 \mu \mathrm{g}$ injected intraperitoneally) induced ALI with severe inflammation. In addition, $10 \mu \mathrm{g}$ of flagellin administration induced significantly increased macrophage infiltration in livers. ${ }^{33}$ Furthermore, flagellin $(5 \mu \mathrm{g}$ per mouse intraperitoneally) activates proapoptotic signaling in mouse tissues, including livers. ${ }^{34}$ Contrary to these findings, pretreatment of flagellin (125 ng per mouse intraperitoneally) enhances bacterial clearance, resulting in a reduction of inflammatory responses in a murine model of Pseudomonas aeruginosa keratitis. ${ }^{35}$ On the basis of these results, we chose the dose of flagellin ( $1 \mu \mathrm{g}$ per mouse intraperitoneally), and our results indicate that there were no hepatotoxic effects associated with this dose of flagellin. Interestingly, we found that TLR5 activation induced by flagellin injection significantly decreased BDL- or $\mathrm{CCl}_{4}$-induced liver fibrosis. Moreover, we found that flagellin injection in fibrotic mice markedly up-regulated the expression of IFN $\beta$ and ILIRN, accompanied by decreased fibroinflammatory responses. These results were further supported by previous findings that TLR5 activation by flagellin induces IFN $\beta^{36}$ and IL1RN production. ${ }^{37}$ Several lines of evidence indicate that type I IFN is closely associated with the progression of liver fibrosis. 
IFN $\beta$ directly inhibits several profibrogenic factors in concanavalin $\mathrm{A}$-induced liver fibrosis. ${ }^{38}$ In addition, IFN $\beta$ significantly reduced liver fibrosis with accompanying reduced expression levels of TLR4 adaptor molecule MyD88. ${ }^{39}$ IFNAR1-lacking mice also showed significantly increased susceptibility to hepatotoxin- or cholestasisinduced liver fibrosis. ${ }^{18}$ Furthermore, the hepatoprotective type 1 IFN-IL1RN axis has been well documented in several types of liver injuries, such as RNA- and DNA-induced liver injury associated with TLR3 and TLR9, respectively. ${ }^{40,41}$ Therefore, we further verify the role of flagellinmediated TLR5 signaling in the progression of liver fibrosis in the type 1 IFN signaling-deficient condition. As expected, increased fibrotic lesions were observed in the livers of IFNAR1-deficient mice compared with those of WT mice. Notably, exacerbated liver fibrosis was observed in IFNAR1-deficient mice, compared with WT mice, on flagellin-mediated TLR5 activation. Furthermore, decreased IL1RN production concomitant with increased inflammation was observed in type 1 IFN signaling-deficient milieu, as confirmed by our in vitro or in vivo experiments. These results suggest that IL1RN levels were not enough to exert anti-inflammatory and antifibrogenic activities without type 1 IFN signaling, even though increased IL1RN production was observed in type I IFN-deficient mice on flagellinmediated TLR5 activation. Moreover, a recent study found that IFN $\beta$-mediated IL-10 autocrine signaling loop contributes to the inhibition of inflammasome activation and its related IL1 $\beta$ production, ${ }^{42}$ suggesting that type 1 IFN signaling is indispensable for the protection of chronic liver injury-associated inflammation and fibrosis. Collectively, our findings indicate that the imbalance between IL1 $\beta$ and IL1RN is determined by the presence or absence of type 1 IFN signaling on flagellin-mediated TLR5 activation and consequently determines the disease phenotype of liver fibrosis. However, overactivation of TLR5 signaling by high-dose flagellin causes acute hepatic injury and its related inflammation and oxidative stress, ${ }^{33}$ indicating that the role of TLR5 signaling induced by flagellin might be in a doseand/or time-dependent manner in livers.

HSCs are located in the perisinusoidal tissue space of the liver, alias the space of Disse. ${ }^{43}$ In healthy liver, HSCs were found in a quiescent state, which contains numerous vitamin A lipid droplets in the cytoplasm. When activated in response to liver injury, these cells undergo transdifferentiation into myofibroblast-like cells, resulting in robust production of extracellular matrix protein, promoting liver fibrosis. ${ }^{44}$ Because of their pivotal roles in the progression of liver fibrosis, modulation of their activation is an emerging target for the prevention or resolution of liver fibrosis. Therefore, on the basis of previous findings that the stimulation of TLR5 signaling with flagellin decreased the expression of type 1 collagen in scleroderma dermal fibroblast, ${ }^{48}$ we first evaluated the role of flagellin on fibrogenic responses in HSCs. However, there was no significant difference of profibrogenic gene expression in activated HSCs by flagellin (Supplemental Figure S5). This result, combined with the results of the lowest expression levels of TLR5 in HSCs than other hepatic cells (Supplemental Figure S3B), indicates that in vivo stimulation of TLR5 by flagellin might not directly affect the activation of HSCs. These results were not consistent with the role of TLR4 on HSC activation via the Myd88-NF- $\mathrm{B}$ signaling pathway. ${ }^{31,45}$ Because flagellin-mediated TLR5 signaling could induce IL1RN production, we next evaluated the role of IL1RN on HSC activation and its associated fibrogenic responses. Consistent with previous results that IL1RN treatment in fibrotic mice significantly reduced the severity of liver fibrosis, ${ }^{18} \mathrm{IL} 1 \mathrm{RN}$ significantly reduced fibrogenic responses and decreased HSC activation, as confirmed by reduced NF- $\kappa \mathrm{B}$ activation and STAT3 activation. These results were further supported by a recent study that found that treatment of IL1RN significantly inhibits IL1 $\beta$-induced HSC proliferation. ${ }^{46}$

Taken together, our findings indicate that TLR5 activation-induced type 1 IFN signaling protects against liver fibrosis by maintaining a balance between $\operatorname{IL} 1 \beta$ and IL1RN production. Stimulation of TLR5 signaling with flagellin predominantly occurred in hepatocytes, leading to type 1 IFN production, which in turn induces antiinflammatory and antifibrogenic IL1RN in KCs. In addition, we found that type 1 IFN plays a key role in the protective effects of flagellin via modulating IL1RN production because of increased liver fibrosis without type 1 IFN signaling pathway (Figure 9). On the basis of previous findings of the protective effects of a TLR5 agonist, CBLB502, on pneumonitis and pulmonary fibrosis, ${ }^{47}$ modulation of TLR5 signaling might pave the way toward developing promising therapeutics to improve the severity of liver fibrosis.

\section{Author Contributions}

J.-W.K., Z.Z., and B.K. conceived and designed the study; Z.Z. and J.-W.K. performed the experiments and wrote the manuscript; J.Q. helped with paraffin embedding and collected the data; S.K.E., C.W.L., and B.K. contributed to the critical review of the final manuscript; all authors have read and approved the final version of the manuscript.

\section{Supplemental Data}

Supplemental material for this article can be found at http://doi.org/10.1016/j.ajpath.2019.11.012.

\section{References}

1. Li F, Ma N, Zhao R, Wu G, Zhang Y, Qiao Y, Han D, Xu Y, Xiang Y, Yan B: Overexpression of miR-483-5p/3p cooperate to inhibit mouse liver fibrosis by suppressing the TGF- $\beta$ stimulated HSC s in transgenic mice. J Cell Mol Med 2014, 18:966-974 
2. Bataller R, Brenner DA: Liver fibrosis. J Clin Invest 2005, 115 : 209-218

3. Tripathi A, Debelius J, Brenner DA, Karin M, Loomba R, Schnabl B, Knight R: The gut-liver axis and the intersection with the microbiome. Nat Rev Gastroenterol Hepatol 2018, 15:397-411

4. Dai L-J, Li HY, Guan L-X, Ritchie G, Zhou JX: The therapeutic potential of bone marrow-derived mesenchymal stem cells on hepatic cirrhosis. Stem Cell Res 2009, 2:16-25

5. Kawai T, Akira S: The role of pattern-recognition receptors in innate immunity: update on Toll-like receptors. Nat Immunol 2010, 11:373

6. Rumbo M, Nempont C, Kraehenbuhl J-P, Sirard J-C: Mucosal interplay among commensal and pathogenic bacteria: lessons from flagellin and Toll-like receptor 5. FEBS Lett 2006, 580:2976-2984

7. Mizel SB, Honko AN, Moors MA, Smith PS, West AP: Induction of macrophage nitric oxide production by gram-negative flagellin involves signaling via heteromeric Toll-like receptor 5/Toll-like receptor 4 complexes. J Immunol 2003, 170:6217-6223

8. Hajam IA, Dar PA, Shahnawaz I, Jaume JC, Lee JH: Bacterial flagellin - a potent immunomodulatory agent. Exp Mol Med 2017, 49:e373

9. Chassaing B, Ley RE, Gewirtz AT: Intestinal epithelial cell Toll-like receptor 5 regulates the intestinal microbiota to prevent low-grade inflammation and metabolic syndrome in mice. Gastroenterology 2014, 147:1363-1377.e17

10. Xu Y, Dong H, Ge C, Gao Y, Liu H, Li W, Zhang C: CBLB502 administration protects gut mucosal tissue in ulcerative colitis by inhibiting inflammation. Ann Transl Med 2016, 4:301

11. Wang L, Zhang W, Ge CH, Yin RH, Xiao Y, Zhan YQ, Yu M, Li CY, Ge ZQ, Yang XM: Toll-like receptor 5 signaling restrains $\mathrm{T}$-cell/natural killer T-cell activation and protects against concanavalin A-induced hepatic injury. Hepatology 2017, 65: 2059-2073

12. Burdelya LG, Brackett CM, Kojouharov B, Gitlin II, Leonova KI, Gleiberman AS, Aygun-Sunar S, Veith J, Johnson C, Haderski GJ, Stanhope-Baker P, Allamaneni S, Skitzki J, Zeng M, Martsen E, Medvedev A, Scheblyakov D, Artemicheva NM, Logunov DY, Gintsburg AL, Naroditsky BS, Makarov SS, Gudkov AV: Central role of liver in anticancer and radioprotective activities of Toll-like receptor 5 agonist. Proc Natl Acad Sci U S A 2013, 110: E1857-E1866

13. Etienne-Mesmin L, Vijay-Kumar M, Gewirtz AT, Chassaing B: Hepatocyte toll-like receptor 5 promotes bacterial clearance and protects mice against high-fat diet-induced liver disease. Cell Mol Gastroenterol Hepatol 2016, 2:584-604

14. Yang J, Yan HJC: TLR5: beyond the recognition of flagellin. Cell Mol Immunol 2017, 14:1017-1019

15. Bashiardes S, Shapiro H, Rozin S, Shibolet O, Elinav E: Non-alcoholic fatty liver and the gut microbiota. Mol Metab 2016, 5:782-794

16. Shu M, Huang D-D, Hung Z-A, Hu X-R, Zhang S: Inhibition of MAPK and NF- $\kappa B$ signaling pathways alleviate carbon tetrachloride (CCl 4)-induced liver fibrosis in Toll-like receptor 5 (TLR5) deficiency mice. Biochem Biophys Res Commun 2016, 471:233-239

17. Vijay-Kumar M, Sanders CJ, Taylor RT, Kumar A, Aitken JD, Sitaraman SV, Neish AS, Uematsu S, Akira S, Williams IR: Deletion of TLR5 results in spontaneous colitis in mice. J Clin Invest 2007, 117:3909-3921

18. Roh YS, Park S, Kim JW, Lim CW, Seki E, Kim B: Toll-like receptor 7-mediated type I interferon signaling prevents cholestasis-and hepatotoxin-induced liver fibrosis. Hepatology 2014, 60:237-249

19. Kim J-W, Roh Y-S, Jeong H, Yi H-K, Lee M-H, Lim C-W, Kim B: Spliceosome-associated protein 130 exacerbates alcohol-induced liver injury by inducing NLRP3 inflammasome-mediated IL-1 $\beta$ in mice. Am J Pathol 2018, 188:967-980

20. Zhou Z, Kim JW, Zhao J, Qi J, Choi SJ, Lim CW, Lee M-Y, Lee K, Kim B: Treatment of cigarette smoke extract and condensate differentially potentiates palmitic acid-induced lipotoxicity and steatohepatitis in vitro. Toxicol In Vitro 2018, 52:33-40
21. Luedde T, Schwabe RF: NF-kB in the liver-linking injury, fibrosis and hepatocellular carcinoma. Nat Rev Gastroenterol Hepatol 2011, 8:108

22. Huebener P, Schwabe RF: Regulation of wound healing and organ fibrosis by toll-like receptors. Biochim Biophys Acta 2013, 1832: $1005-1017$

23. Krizhanovsky V, Yon M, Dickins RA, Hearn S, Simon J, Miething C, Yee H, Zender L, Lowe SW: Senescence of activated stellate cells limits liver fibrosis. Cell 2008, 134:657-667

24. Dong Z-X, Su L, Brymora J, Bird C, Xie Q, George J, Wang J-H: Resistin mediates the hepatic stellate cell phenotype. World J Gastroenterol 2013, 19:4475

25. Xiang D-M, Sun W, Ning B-F, Zhou T-F, Li X-F, Zhong W, Cheng Z, Xia M-Y, Wang X, Deng XJG: The HLF/IL-6/STAT3 feedforward circuit drives hepatic stellate cell activation to promote liver fibrosis. Gut 2018, 67:1704-1715

26. Wang F-p, Li L, Li J, Wang J-y, Wang L-y, Jiang W: High mobility group box-1 promotes the proliferation and migration of hepatic stellate cells via TLR4-dependent signal pathways of PI3K/Akt and JNK. PLoS One 2013, 8:e64373

27. Gan LT, Van Rooyen DM, Koina ME, McCuskey RS, Teoh NC, Farrell GC: Hepatocyte free cholesterol lipotoxicity results from JNK1-mediated mitochondrial injury and is HMGB1 and TLR4dependent. J Hepatol 2014, 61:1376-1384

28. Watanabe A, Hashmi A, Gomes DA, Town T, Badou A, Flavell RA, Mehal WZ: Apoptotic hepatocyte DNA inhibits hepatic stellate cell chemotaxis via toll-like receptor 9. Hepatology 2007, 46:1509-1518

29. Brun P, Castagliuolo I, Leo VD, Buda A, Pinzani M, Palù G Martines D: Increased intestinal permeability in obese mice: new evidence in the pathogenesis of nonalcoholic steatohepatitis. Am J Physiol Gastrointest Liver Physiol 2007, 292:G518-G525

30. Carotti S, Guarino MPL, Vespasiani-Gentilucci U, Morini S: Starring role of toll-like receptor-4 activation in the gut-liver axis. World J Gastrointest Pathophysiol 2015, 6:99

31. Seki E, De Minicis S, Österreicher CH, Kluwe J, Osawa Y, Brenner DA, Schwabe RF: TLR4 enhances TGF- $\beta$ signaling and hepatic fibrosis. Nat Med 2007, 13:1324

32. Gäbele E, Mühlbauer M, Dorn C, Weiss TS, Froh M, Schnabl B, Wiest R, Schölmerich J, Obermeier F, Hellerbrand C: Role of TLR9 in hepatic stellate cells and experimental liver fibrosis. Biochem Biophys Res Commun 2008, 376:271-276

33. Xiao Y, Liu F, Yang J, Zhong M, Zhang E, Li Y, Zhou D, Cao Y, Li W, Yu J: Over-activation of TLR5 signaling by high-dose flagellin induces liver injury in mice. Cell Mol Immunol 2015, 12:729

34. Rolli J, Loukili N, Levrand S, Rosenblatt-Velin N, Rignault-Clerc S, Waeber B, Feihl F, Pacher P, Liaudet L: Bacterial flagellin elicits widespread innate immune defense mechanisms, apoptotic signaling, and a sepsis-like systemic inflammatory response in mice. Crit Care 2010, 14:R160

35. Kumar A, Hazlett LD, Yu FS: Flagellin suppresses the inflammatory response and enhances bacterial clearance in a murine model of Pseudomonas aeruginosa keratitis. Infect Immun 2008, 76:89-96

36. Ha H, Lee J-H, Kim H-N, Kwak HB, Kim H-M, Lee SE, Rhee JH, Kim H-H, Lee ZH: Stimulation by TLR5 modulates osteoclast differentiation through STAT1/IFN- $\beta$. J Immunol 2008, 180: 1382-1389

37. Carvalho FA, Aitken JD, Gewirtz AT, Vijay-Kumar M: TLR5 activation induces secretory interleukin-1 receptor antagonist (sIL-1Ra) and reduces inflammasome-associated tissue damage. Mucosal Immunol 2011, 4:102

38. Tanabe J, Izawa A, Takemi N, Miyauchi Y, Torii Y, Tsuchiyama H, Suzuki T, Sone S, Ando K: Interferon- $\beta$ reduces the mouse liver fibrosis induced by repeated administration of concanavalin A via the direct and indirect effects. Immunology 2007, 122:562-570

39. Shimozono R, Nishimura K, Akiyama H, Funamoto S, Izawa A, Sai T, Kunita K, Kainoh M, Suzuki T, Kawada N: Interferon- $\beta$ mediates signaling pathways uniquely regulated in hepatic stellate cells 
and attenuates the progression of hepatic fibrosis in a dietary mouse model. J Interferon Cytokine Res 2015, 35:464-473

40. Conrad E, Resch TK, Gogesch P, Kalinke U, Bechmann I, Bogdan C, Waibler Z: Protection against RNA-induced liver damage by myeloid cells requires type I interferon and IL-1 receptor antagonist in mice. Hepatology 2014, 59:1555-1563

41. Petrasek J, Dolganiuc A, Csak T, Kurt-Jones EA, Szabo G: Type I interferons protect from toll-like receptor 9-associated liver injury and regulate IL-1 receptor antagonist in mice. Gastroenterology 2011, 140:697-708.e4

42. Guarda G, Braun M, Staehli F, Tardivel A, Mattmann C, Förster I, Farlik M, Decker T, Du Pasquier RA, Romero P: Type I interferon inhibits interleukin-1 production and inflammasome activation. Immunity 2011, 34:213-223

43. Yin C, Evason KJ, Asahina K, Stainier DY: Hepatic stellate cells in liver development, regeneration, and cancer. J Clin Invest 2013, 123: $1902-1910$

44. de Oliveira da Silva B, Ramos LF, Moraes KC: Molecular interplays in hepatic stellate cells: apoptosis, senescence, and phenotype reversion as cellular connections that modulate liver fibrosis. Cell Biol Int 2017, 41:946-959

45. Liu M, Xu Y, Han X, Yin L, Xu L, Qi Y, Zhao Y, Liu K, Peng J: Dioscin alleviates alcoholic liver fibrosis by attenuating hepatic stellate cell activation via the TLR4/MyD88/NF- $\mathrm{B}$ signaling pathway. Sci Rep 2015, 5:18038

46. Reiter FP, Wimmer R, Wottke L, Artmann R, Nagel JM, Carranza MO, Mayr D, Rust C, Fickert P, Trauner M: Role of interleukin-1 and its antagonism of hepatic stellate cell proliferation and liver fibrosis in the Abcb4-/-mouse model. World J Hepatol 2016, 8:401

47. Wang Z-D, Qiao Y-L, Tian X-F, Zhang X-Q, Zhou S-X, Liu H-X, Chen Y: Toll-like receptor 5 agonism protects mice from radiation pneumonitis and pulmonary fibrosis. Asian Pac J Cancer Prev 2012, $13: 4763-4767$

48. Sakoguchi A, Nakayama W, Jinnin M, Wang Z, Yamane K, Aoi J, Makino K, Kajihara I, Ichihara A, Makino T, Fukushima S, Sakai K, Inoue $\mathrm{Y}$, Ihn $\mathrm{H}$ : The expression profile of the toll-like receptor family in scleroderma dermal fibroblasts. Clin Exp Rheumatol 2014, 32: S4-S9 